\title{
BLOCKCHAIN, LEADERSHIP AND MANAGEMENT: BUSINESS AS USUAL OR RADICAL DISRUPTION?
}

\author{
Theodore C. Chartier-Rueg \\ Strategy and Communication Advisor \\ Les Entretiens de Royaumont \\ St. Gallen University (HSG) \\ Dufourstrasse 90, CH-9000 St. Gallen \\ theodore.chartier-rueg@student.unisg.ch \\ Thomas D. Zweifel \\ Guest Professor \\ St. Gallen University (HSG) \\ Dufourstrasse 90, CH-9000 St. Gallen \\ thomas.zweifel@unisg.ch
}

\begin{abstract}
The Internet provided the world with interconnection. However, it did not provide it with trust. Trust is lacking everywhere in our society and is the reason for the existence of powerful intermediaries aggregating power. Trust is what prevents the digital world to take over. This has consequences for organisations: they are inefficient because time, energy, money and passion are wasted on verifying everything happens as decided. Managers play the role of intermediaries in such case: they connect experts with each others and instruct them of what to do. As a result, in our expert society, people's engagement is low because no one is there to inspire and empower them. In other words, our society faces an unprecedented lack of leadership. Provided all those shortcomings, the study imagines the potential repercussions, especially in the context of management, of implementing a blockchain infrastructure in any type of organisation. Indeed, the blockchain technology seems to be able to remedy to those issues, for this distributed and immutable ledger provides security, decentralisation and transparency. In the context of a blockchain economy, the findings show that value creation will be rearranged, with experts directly collaborating with each others, and hierarchy being eliminated. This could, in turn, render managers obsolete, as a blockchain infrastructure will automate most of the tasks. As a result, only a strong, action-oriented, leadership would maintain the organisation together. This leadership-in-action would consist in igniting people to take action; coach members of the organisations so that their contribution makes sense in the greater context of life.
\end{abstract}

Keywords: leadership in-action; blockchain emergence in organisations; disruptive managerial methods; blockchain practices; organisational agility; holacracy and consensual decision practice; expert society with autonomy of actors.

\section{Introduction}

"If you don't believe me or don't get it, I don't have time to try to convince you, sorry." Satoshi Nakamoto, creator of the Bitcoin, the first Blockchain, July $29^{\text {th }}, 2010$.

When one looks at the fundamentals of transactions in the human world, trust appears as the key element. It is on trust that relies our ability to exchange any kind of values or to decide in the context of uncertainty. Trust, however, lacks in our society. People hedge themselves against uncertainty because they have low confidence in the system; and the digital era worsened the situation: digital frauds massively happen every day affecting each and everyone of us [1]. It also affects organisations; instead of being a place where trust unites members, hierarchy serves this purpose by exercising control over employees and make them respect the rules [2]. It is used inefficiently, based on assumptions that the society still functions as it did in the previous century. In such case, leadership is only perceived as an add-on to effective management, which goes against the belief of great leaders that keep emphasising trust and inspiration as pre-requisite to the effective functioning of an organisation. Christophe de Margerie [3], former CEO of Total, made trust and confidence in times ahead essential components of his leadership, whether it was with his business partners or his employees [4]. Without confidence that the other party will perform his duty and will do so 
correctly, one is paralysed and keeps planning B, C, D-Z plans to counter the potential deception by the other party. That is why it is crucial to resolve this problem of trust.

In 2008, someone under the pseudonym of Satoshi Nakamoto understood that the best way to resolve it was to create a platform which would be trusted and that people would be incentivised to keep secure [5]. The first blockchain, the Bitcoin's, was born. Nowadays, everybody talks about blockchain; Google trends shows that it has never been so looked up. In December 2015, blockchain gave 1,650,000 results on Google; 3,940,000 in 2016 and 16,800,000 in May 2017. Yet, in 2017, it is still $90 \%$ less popular than the term 'Bitcoin', although blockchain is Bitcoin's underlying technology [6]. In all likelihood, this comes from the fact that the technology itself is hardly understoodprobably one of the least understood technology in 2017 [7]. Its (yet) most popular and lucrative application is thus of much more interest. It shows that, although people perceived the disruptive nature of the technology, confusion exists around blockchains, their functioning and their implications. Despite the euphoria, it seems to remain difficult to grasp the concept as a whole [7]. Filtering out the technological jargon, experts vulgarise the blockchain technology as "a distributed and immutable (write once and read only) record of digital events that is shared peer to peer between different parties (networked database systems)" [7]. It guarantees the veracity of an information, without revealing the information itself.

Since 2015, the technology has become of extreme interest for a few pioneers. Many of the world's biggest firms came together to research and develop potential applications, such as in the recently founded Enterprise Ethereum Alliance gathering Microsoft, UBS or Intel [8]. This supports the view of blockchain experts, such Don and Alex Tapscott, that a blockchain revolution is happening and that, eventually, the world will shift towards a blockchain economy $[9,10]$. There is no time to waste to start the shift, as it will significantly affect each of us, in the same or maybe even greater manner, than computers and the Internet did. This comparison makes sense, for the underlying technology of the World Wide Web [11] was (and is) poorly understood, whereas its possibilities are well grasped and used. In other words, focus ought not to be put on understanding the technology, but rather on exploring its prospects. In this manner, it is crucial to distinguish the hype from the reality [7]. For instance, many exclusively focus on the financial implications of the technology, supporting, like former superintendent of financial services in the state of New-York Ben Lawsky, that the industry will be unrecognisable within five to ten years [10]. Although not wrong, their vision is confined to only one of the numerous potential prospects of the technology evidenced in Don and Alex Tapscott's book, Blockchain Revolution [10].

One aspect very few consider is the consequences for organisations resulting from a massive adoption of the blockchain technology. Indeed, if the technology provides direct trustable communication between stakeholders, it might significantly disrupt the functioning, as well as the roles within an organisation [12]. If such is the case, managers might be compelled to adapt their behaviour to serve other (better) purposes. In other words, what are the implications of the emergence of blockchain for leaders and managers in organisations?

The main objective of this research is to analyse the repercussions of the adoption of the blockchain technology on organisations, and, through that, establish a conclusive evaluation of the leadership implications of such repercussions. This will be achieved by giving a general depiction of what the blockchain technology encompasses, as well as what its implementation means in the context of an organisation. Furthermore, this paper will try to determine and investigate the factors shaping the structure and boundaries of an organisation. Special emphasis will be held on the development of decentralised and distributed systems enabled by blockchain implementation, in opposition to current hierarchical designs. The implications for leadership practices will be integral to this investigation, for, as it will be shown, they might significantly differ if the developments occur as envisioned. To this end, the Global Leader Pyramid by Thomas Zweifel will serve as a leadership framework. In order to visualise the effects and significance of these potential developments, a detailed analysis will consider how the use of the blockchain technology and the results obtained by this research would apply to a Harvard Business Case that describes a company aiming at decentralisation and distribution of authority without the help of the blockchain technology. 


\section{Introduction To The Blockchain Technology}

\section{1. The Trust Protocol}

\section{1. 1. The Need of Trust}

The problem with what one calls the Internet (really the World Wide Web) is that it is based on the idea that everyone will act collaboratively without the intention to harm each other. In the early days of the World Wide Web at the CERN and in the USA, no security was needed because only few people used it and all of them were researchers. Moreover, the protocol on which it is based (i. e. HTTP) made it possible to check who was the owner of the IP address and contact him in case of unacceptable behaviour. However, days have passed and the number of users makes it impossible to know who is who and who to trust. As a result, the World Wide Web has become a dangerous and hardly trusted place. Scams and data stolen are more than frequent: all of the Fortune 500 corporations got hacked and roughly $\$ 80$ billion worth of data get lost every year [1]. This restricts the possibility of total virtualisation. A "leap of faith" is necessary to transact over the Internet [10]. There is a need of trust and security for people to fully virtualise their activities. It is strongly believed that this absence of confidence is restricting future developments and efficiency growth [10].

\section{1. 2. Trust in the Digital Age}

Tapscott and Ticoll described the four principles of trust in the digital age in their book The naked corporation [13]. Those are honesty, consideration, accountability and transparency [12]. Currently, we live in a world where business is already poorly trusted. Confidence in transactions therefore arises from parties acting with integrity towards those four principles [14]. With such considerations a massive virtualisation of transactions and interactions seems improbable. Security and trust will always remain an issue because the four principles always depend on the integrity of each party involved in the transaction including a possible middleman who would secure the transaction (e. g. a bank for card payments). However, in line with the recent scandals on data hacking or sale of personal data, those intermediaries are less and less trusted [1].

\section{2. A Distributed Ledger Providing Trust}

\section{2. 1. Designing the Ledger}

The solution is to find a way to obtain a fully secure peer-to-peer (i.e. person-to- person) transaction, and eliminating a possible middleman for efficiency reasons. Such a technology is required for proper virtual business where physical control is impossible. Actually, such a technology already exists and is familiar to anyone: end-to-end cryptography. Apple and later Whatsapp made the news as they decided to secure their messaging services using this technology [15]. It consists, via a public and private key, in encrypting a message with a public key that only the associated private key can decrypt. This is referred to hashing: anything that goes through this cryptographic digest (SHA-256) gives a long code and the same code can only be obtained by providing the exact same information (e. g. same text message). Such a technology (SHA-256) is also used by Bitcoins, a famous peer-to-peer currency with full security where no middleman is involved. It is the technology behind Bitcoins that is of most interest: blockchain.

\section{2. 2. The Blockchain Technology}

The blockchain technology enables the transfer of any piece of information (e.g. the amount of Bitcoin) while recording any changes that occurred to this piece of information [5]. The blockchain is distributed: it runs entirely on each user's computer (called nodes) and uses their computing power to verify each transaction. Whenever a transaction is performed (e. g. $10 \$$ from X to Y), it is cleared and registered in the ledger to later be part of a new 'block' [5]. Each new transaction must refer to a previous block/transaction (e. g. X received $10 \$$ beforehand) in order to be validated; hence block-chain. Thus, every event is permanently registered on the ledger. Finally, the entire technology provides full anonymity as each transaction does not regard the performers but rather what is performed [5]. Transactions are encrypted from end-to-end: each person has a public and 
private key which ensures that the identity of the parties is undisclosed, while the entire world is aware that a transaction occurred; e. g. 10 \$ were transferred.

As a result, honesty necessarily arises as no scam is possible (e. g. X must have the $10 \$$ in order to perform the transaction); the initial conditions are always true. Moreover, only two parties are involved: the performer and the receiver. No need of a middleman to ensure honesty. Moreover, decentralisation and anonymity prevents any discrimination regarding the transaction. This latter is only fact based; e. g. same influence from a 12 year old than from a JPMorgan executive [16]. Finally, because the blockchain is decentralised, fully accessible and constantly verified, accountability and transparency are ensured. It is possible to inspect whether a transaction effectively occurred; anytime, anywhere. As stated by Don Tapscott and his son Alex, "This new digital ledger of economic transactions can be programmed to record virtually everything of value and importance to humankind" [10].

Numerous blockchains already exist or are being developed by consortium such as R3. Of the available ones, the most popular are Bitcoin, Hyperledger (IBM) and Ethereum. The main feature of the latter is the possibility to code self-executing transactions. Those are referred to as smart-contracts, and will be further described later in the paper. Verification in most blockchains occurs through what is called proof of work: computing power is used to store and resolve problems. Solving those problems is rewarded by tokens (e. g. Bitcoins). Solving of those problems ensures security because it verifies the previous transactions in the chain and computes a new key which will allow the miner to link the transaction to the other previous blocks (i. e. the chain). Fig. 1 depicts blocks creation (called mining), which verifies new transactions. The higher the reward, the higher the security. As a result, because everyone benefits from taking part in the verification, the system is secure and is hardly falsifiable. In order to alter it, one would need to modify the entire blockchain on every computer running it and this at the exact same time without being caught by the same computers controlling the blockchain.

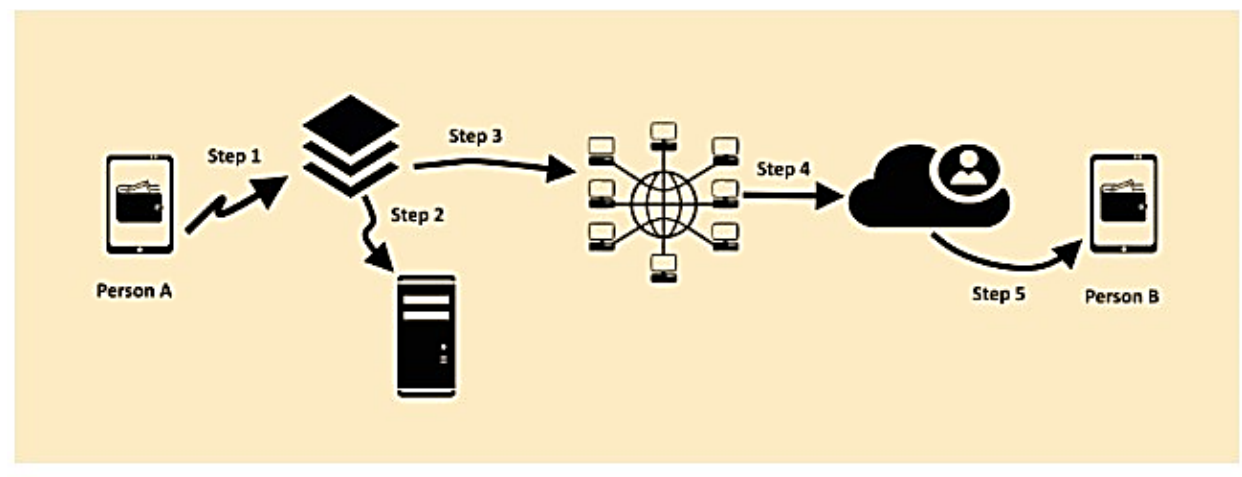

Step 1: Person A initiates a transaction and includes digital signature inside transaction

Step 2: Transaction is sent to miner. Miner is one type of verifier that verifies all transaction of connected nodes

Step 3: Miner broadcasts transaction as block to all connected nodes if transaction is valid

Step 4: Node inside network accepts block if all transaction inside it are valid and not already spent. After ownership of block inside network and transaction is transferred into target account inside block is sent to person B

Step 5: Person B gets money (digital currency)

Fig. 1. The Workflow Of Blockchains, as depicted by ifourtechnolab.com (2016)

\section{2. 3. A Trusted Collaborative Ledger}

Another advantage the distributed ledger offers is the possibility of knowing the behaviour of each anonymous user running the blockchain. Not only does this makes transparency and consideration greater, it also offers the possibility for a decentralised, honest, rating system [17]. Imagine a blockchain-based open directory or a web search engine for one specific matter. It lists all the persons offering to perform a specific transaction. Any transaction, which was successfully performed according to spe- 
cific criteria inherent to the transaction, is therefore classified as positive [17]. Such a system would comprise a client-controlled system instead of a community-controlled reputation (as it currently is the case for Ebay, Amazon or Uber etc.). That is, the client calculates the reputation score based on parameters set by them, which restricts abuse possibilities; e. g. multiple transactions performed between friends; multiple profile with the actual same identity [17]. Moreover, imagine programs that would access and use the data provided by the blockchain. The blockchain directory itself could then weight the transactions so that multiple transactions between the same peers would be weighted appropriately and seen as consumer fidelity and thus quality. The program would calculate the reputation of each 'performer' by computing the transactions list from the blockchain and the note attributed to each of the performers over time [17]. As a result, the blockchain-based open directory would display each performer along with its rating over time. It would moreover increase the consideration principle of the digital age, for a fairer value would be attributed to each transactions based on the quality of their performance.

\section{3. The Black Box: Virtualising Private Data}

Because the blockchain offers trust in the digital age through this distributed ledger, it permits the virtualisation and the protection of one's online data. Don Tapscott introduces this as the "blackbox" [10]. The concept of the blackbox is simple: both parties know that information within the blackbox is valid and true. This is not currently the case. Nowadays, although the other party requires only one piece of information, many must be divulged for verification purposes. The problem of the driving license illustrates it best [10]. A car rental company should only know whether one may drive and rent a car (e. g. is over 21). However, for security purposes, a driving license provides much more information such as one's birth date, birth place or nationality. At each car rental, those data are checked and recorded, thus being disclosed online and potentially subject to misuse. Because the blockchain provides the possibility for an information to be correct from the beginning without the possibility to falsify it later on, verification only occurs at the entry of the information [10]. As a result, imagine that the blackbox represents the data contained by one's driving license. Whenever he or she wants to rent a car, the company's software (running on the same blockchain) would ask the person's blackbox whether he or she has a driving license and whether she or he is over 21 . No other information would have to be disclosed. The information is necessarily right and it is all that matters, the rental company does not need to know more.

The blackbox provides the opportunity to answer in a binary way to questions (yes/no) without the need of providing supporting proof, as the answer can only be true. The CEO of Consensus Systems, Joseph Lubin, talks here about a "canonical persona" [18]. Instead of having one version of one's digital self, one would be able to disclose the same information as one does in real life: one does not talk about its chemotherapy to its recent business acquaintances; one does so with his doctor. As a result, private information on the blockchain gives one the ability to have full control over the data they share. One can even differentiate between different 'versions' of oneself: business, family, doctor [18]. Eventually, it opens up the monetising of one's own data while keeping a control over it. Moreover, the blackbox concept has implications towards the reputation system offered by a blockchain-based directory. It may provide for greater and fairer opportunity of chances while getting around corruption in developing country [10]. No need (and possibility) for an African entrepreneur to corrupt his banker to obtain a loan; one's 'business blackbox' is one's reputation. The facts are all that matter. It will be able to answer for you all the questions a banker usually asks and which often trigger discrimination.

\section{4. Current Applications}

The main characteristic of a blockchain based network is decentralisation. It allows people (i. e. peers) to interact directly with each other, without a 'trusted' middleman acting both as verifier and organiser of the transactions performed who eventually deduct a fee for its performance. As a result, the possibility of a true sharing economy with direct peer-to-peer transactions emerges [10]. Currently, services, which are often referred to as part of the sharing economy actually lie at the heart an aggregating economy. Companies like Uber or Airbnb do nothing more than aggregating people which provide services to each other, because those companies provide a central and unique governance [19]. What blockchain may eventually bring to those companies is true 
sharing through decentralisation. The extreme example of a Distributed Autonomous Organisation (or DAO) is a way to illustrate such an impact [20]. DAOs are virtual organisations, in which owners and contributors are bound by an online (smart) contract. They democratically decide how to conduct business and how to allocate funds [20]. In the case of Uber or Aibnb for instance, a DAO could replace the company and be owned by its members, which would collaboratively work in order to all share their own capital [10]. The aggregators (e. g. Uber or Airbnb) would not make owners pay for their sharing; peers would all work directly with each other.

More appropriate and realistic examples are the use of dApps (decentralised apps) by companies [10]. Running on a blockchain (like Ethereum), they would thus also be run by the customers. They would be those open-directories previously mentioned; thus enabling the rating system and all the other features, especially regarding security, provided by the blockchain in general. Currently, the firm ConsenSys is dedicated to developing such dApps to run on the Ethereum blockchain. Another example of a dApp is a blackbox app we previously mentioned, which contains your entire identity. An existing example is uPort (upport.me).

A 'physical' implementation of the possibilities offered by the blockchain technology is currently instated by the company Everledger [21]. By using the Hyperledger blockchain, they collect and then permanently record a diamond's defining characteristics (3D scanning) in the global secure ledger [21]. Various stakeholders, running the same platform, may access the information along the value chain of the diamond, so that counterfeits are easily identified. Future prospects are to extend the process to the mining conditions, in order to certify that diamonds are conflict-free (so called 'blood-diamonds').

Finally, the enterprise 21 Inc. or OpenBazaar offer decentralisation of transactions through the Bitcoin blockchain. 21 Inc. let people actively participate and be rewarded for their participation in the blockchain and any other activity they might undertake using it, such as messaging each other [22]. For instance, if one wants to contact you for any professional matter, similar to the LinkedIn messaging, you could be rewarded. The company also offers the possibility to share your small computing power in order to validate blockchain transactions. OpenBazaar is simply a peer-to-peer eBay which lets people interact and sell directly with each other, using the Bitcoin blockchain in order to validate, anonymise and secure transactions. Many potential applications, including those previously mentioned, are depicted in Fig. 2, which supports the eventuality of a blockchain-based economy.

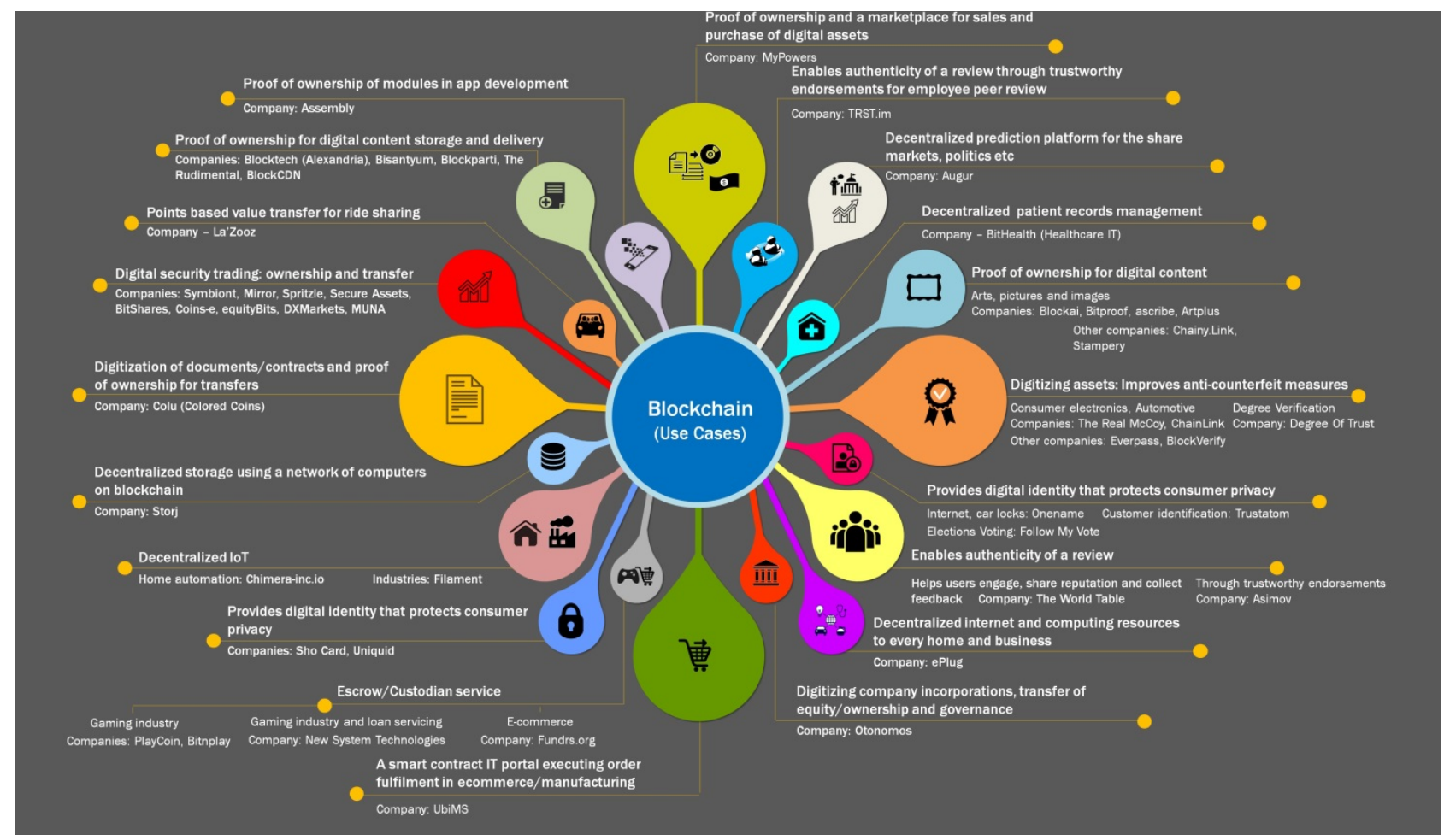

Fig. 2. Blockchain Use Cases: Comprehensive Analysis \& Startups Involved. [23] 


\section{The Blockchain Economy}

\section{1. Smart Contracts}

Vitalik Buterin, the creator of the Ethereum blockchain, defines smart contracts as "systems which automatically move digital assets according to arbitrary pre-specified rules" [20]. Smart contracts are the heart of the Ethereum blockchain. It is possible to create extended smart-contracts with a lot of code; i. e. a decentralised application (dApp). Each smart contract runs on the entire distributed ledger (e. g. Ethereum), and may codify interactions between participants of the ledger. A firm can therefore be run entirely by smart contracts. This is the case for those above-mentioned DAOs [20]. By codifying members' interactions via smart-contracts, shareholders could receive a precise percentage of the income or could democratically decide regarding important matters, etc. Smart-contracts, which would establish firms, should be perceived as online, self-executing articles of associations. They can also regulate transactions and release payment only in case of due performance, provide for part-payments if defects arise, etc. Smart contracts can be employed for nearly everything within organisations in order to regulate its 'hard' functioning [24]. They would be the result of precise negotiations, just like normal contracts.

\section{2. The Seven Design Principles of a Blockchain Economy}

Following numerous interview and research for their book, Blockchain Revolution, Don and Alex Tapscott came up with seven principles of a blockchain-based economy [10]. By scouting the trends developing in the blockchain community, they identified the main characteristics of a working blockchain economy.

Networked Integrity. Networked integrity resolves the 'leap of faith' ones currently need to have to transact over the Internet. The belief that the other party will act with integrity is now intrinsic and is not questioned because the transaction is secure regardless of how the other party acts.

Distributed Power. The power is in the hand of the people; everyone may access transact and secure a blockchain. There is a possibility to largely distribute power (Brody as cited in [10]). Indeed, nowadays anything is a computer with much more power than it actually needs: fridges, wash machines or even some toilets. Why not use them for the sake of verifying the blockchain? No need for financial reward, as the simple knowledge that everyone in the world contributes to making the digital world a safer place is rewarding enough. The company 21 , Inc. gives the opportunity to distribute power on the Bitcoin blockchain [22]. The company launched a small Application Specific Computer (ASIC) dedicated to bitcoin-specific applications such as mining; with the possibility to install dApps that, for instance, offer a paid proxy to Internet users.

Value as Incentive. Nakomoto understood game theory when he coded the Bitcoin blockchain [10]. He knew that people, which are part of the platform, would behave egoistically and choose the most interesting outcome for them. As a result, he coded the system so that their best response would be to maintain the system: be a node and mine in order to secure each transactions. The rewarding system of the Bitcoin is designed so that a block creation is rewarded by bitcoins, which "adds an incentive for nodes to support the network" (Nakomoto as cited in [10]). As a result, the parties of a smart contract both have interest in the contract to be secure as they do not want the other party to take advantage of them. In other words, deceitful behaviour is (financially) costly on a blockchain [10].

Security. The blockchain technology relies on SHA-256, which is the highest cryptographic algorithm. The way the blocks are linked together and verified, i.e. proof of work and consensus, makes it extremely hard for anyone to hack transactions. A $51 \%$ attack, where the same person owns $51 \%$ of the whole blockchain computing power, is currently viewed as the only way to hijack it. Moreover, the decentralisation of the platform makes it more secure: no vault exists where data is contained; only transactions describing what it involved exist and are linked to all the other past and future transactions.

Privacy. Privacy is seen as the central issue of the digital age. Transactions on the blockchain are not concerned with this problem as they are always $100 \%$ anonymised. There is no link between the performer of the transaction and its actual online data. The blackbox apps are here an example of the possibility for users to digitalise their private data and keep them private by own- 
ing them. A startup such as Personal Blackbox Company is developing means for corporations to develop new data relationships, for corporations now realise they would be better off with anonymised reliable data rather than multiple avatars disclosing misleading information (Haluk Kulin as cited in [10]). A new web running a blockchain would actually protect privacy, for it will let owners remain master of their data. They would even be able to earn money by being able to sell their actual and reliable data, as offered by [25].

Rights Preserved. They do not only refers to intellectual property. To a larger extend, they encompass the rights to be heard and one's contribution to be acknowledged. In the early days of the Internet, collaboration was what drove all its users. Deception was nearly inexistent because everyone knew and respected each other. Each member's contribution was acknowledged; sometimes rewarded, e. g. forums. Nowadays, an idea is easily stolen and untraceable when faced with the petabytes of data on the Internet. At the same time, the data people create are not their own anymore: Google or Facebook gather them and sell them to corporations. With blockchain, a dApp such as the one developed by Personal Blackbox Company preserves rights of users. Other dApps such as proofofexistence.com timestamps files and attest their proof of existence through a cryptographic digest, which will issue a specific key to the document. Any subsequent change to the file will result in a different hash/key [26]. Through smart contracts, rights can now be asserted, traced and rewarded depending on the rights of the communities' members, just like for Shlager's and Ostrom's pyramid of rights [27]. This applies for usual behaviour over the Internet (e. g. answering polls) but extends to the original idea of the Internet where users can be acknowledged and rewarded for any contribution they make [10]. For instance, Youtube advertising may be better tracked, while performance could be more accurately measured, which will result in the video's owner being better rewarded, while strengthening the company's forecasts and strategy. In corporations, smart contracts regulating rights management systems may eventually emerge, so that organisations' members are better heard and rewarded [10].

Inclusion. The current era of the Internet provides quite low inclusion. Although most people have access to Facebook all over the world, they cannot all do business in the same conditions over the Internet because the physical impeaches the digital. In order to be established, trust, as the central question of the digital era, requires many collateral such as birth certificate or bank statements. With a blockchain-run service, trust exists already, therefore enabling millions (or billions) of new users, whose administration or legal system prevent to access the current version of the Internet. By using a blockchain-based transactions, those people are now included in the digital world: no need for the administrative paperwork or a fancy computer; trust already exists and transactions can be performed with the simplest smartphone. It should contribute to the economy as a whole. As stated by the World Bank [28] "inclusion is the foundation for prosperity", which is the reason why the blockchain technology might contribute to include more and more people into the economy.

Trust is the sine qua non of the digital economy and the blockchain, a platform providing secure mass collaboration, provides honesty and integrity. In other words, any application of the blockchain technology meets those seven principles of a trusted digital economy that is digital interactions- as imagined by Don Tapscott [10]. It means that it is only a matter of time before transactions are run through a blockchain platform such as Ethereum [12]. As a result, one may expect an exponential development of a blockchain-based economy, which will affect all the actors of our economy; especially organisations.

\section{3. Smart Contracts in the Upcoming Economy}

The possibilities offered by smart contracts on the Ethereum blockchain could be at the core of any organisation. Indeed, they fulfil those principles generally agreed upon by many experts of the Internet and the digital economy such as Don Tapscott, McKinsey [29] or the OECD [30, 31]. All strongly believe that only a platform which guarantees those principles will enact further developments and migration towards the digital age [30]. Therefore, a bright future might await the Ethereum blockchain, as it could lie at the core of many organisations. In such case, smart contracts will regulate most if not all transactions within firms. They can establish an organisation like articles of association do, while automatically enforcing its articles at any time. Furthermore, because 
the above mentioned principles are fulfilled, there would be no need to question the reliability of any the transactions occurring within (or with) the organisation.

Many possibilities are offered to organisations in order to develop themselves around the blockchain technology. Companies could use the Ethereum blockchain, with the possibility to become a DAO with shareholders owning the tokens. Firms may also develop their own platform, e.g. multichain or Monax, in order to secure their digital transactions and benefit from all advantages brought by the technology (e. g. security and smart-contracts). Another option which is currently pursued is the development of a consortium blockchain platform so that a multitude of companies within the same industry use it. R3 is the best example of such an alliance in the banking industry: over forty banks such as HSBC or ING combine their forces to develop a distributed ledger called Corda [32]. The platform is distributed only between the members of the consortium; e.g. the forty banks. However, in such a case, the principles of the digital economy do not apply for the end consumers: only the forty banks (as institutions) benefit from it. In such a case, privacy, networked integrity or distributed power only occurs between the people which run the platform (i. e. the forty banks). As a result, this is uninteresting for end users as this is only a way for current third parties to remain in the market by strengthening their position, getting rid of their own third parties (e. g. clearing houses), and simplify inter companies transactions [33]. In other words, it is the implementation of a new type of secure databases with no implication whatsoever for the digital economy -and thus no consequences when it comes to this research [16]. However, with the creation of the Enterprise Ethereum Alliance [25] on February 27th 2017, it seems that world leading companies have opted for the Ethereum blockchain [25]. The EEA, which is a consortium gathering leading experts in various industries such as UBS, Consensys, Intel, or BP acknowledged that a public distributed ledger is the future and they aim develop "general purposes systems" all "compatible with Ethereum" [25]. The EEA puts great emphasis on interoperability of platforms, so that all transactions in a blockchain-based digital economy will eventually rely on Ethereum -a public and distributed blockchain [25]. A current example of interoperability is the btcrelay API developed by ConsenSys so that users may use Bitcoin to operate dApps and smart-contracts on Ethereum. The point is that, although it is likely organisations may develop their own private platforms to store their database or their projects, those private platforms will use the blockchain technology and will be linked to the Ethereum blockchain because the digital economy will happen there 14]. An example would be a smart-contract between the bank and a private person for a loan. The Ethereum blockchain records the smart contract: money is transferred if credit rating requirements are met. To verify the credit rating, the smart contract will question the blockchain of the governmental agency for debt and bankruptcy whether this person meets the credit rating requirements -as stated before, with the blackbox concept, the bank will never know what the person owns. If all is in order, the smart contract on Ethereum will perform the transaction and ask the bank's blockchain to transfer the money, maybe by using another blockchain platform like bitcoin.

The concept of blockchain technology and infrastructure implementation is disruptive, but it should not be perceived as a magic spell solving every issues in each industry. However, it will be an evolutionary journey for every sector adopting the blockchain. A Forbes' article dated from May, $9^{\text {th }} 2017$ [34] explored the potential of the blockchain technology inside the healthcare industry. It affirms that the digitalisation of the industry is a matter of confidence in the system. In this article, Reenita Das, a partner and Senior Vice President of the healthcare consulting company Frost \& Sullivan, states that: "trust and governance within a blockchain network or consortium will be the critical success factors for implementation" [7]. The article depicted the potential consequences of blockchain use on the healthcare industry, especially when it comes to linking the patient generated data (e. g. using IoT like smart-watch or connected implants) and the clinical records and analyses. For clarity purposes, those prospects of blockchain integration within the healthcare industry are depicted in Fig. 3.

The various aspects of the technology can serve many purposes: the consensus aspect permits claim adjudication, the decentral aspect may spur collaboration between actors (e. g. hospital, pharmaceutical, administration), the distributive and immutable characteristics provides security and control for sensitive health data. 


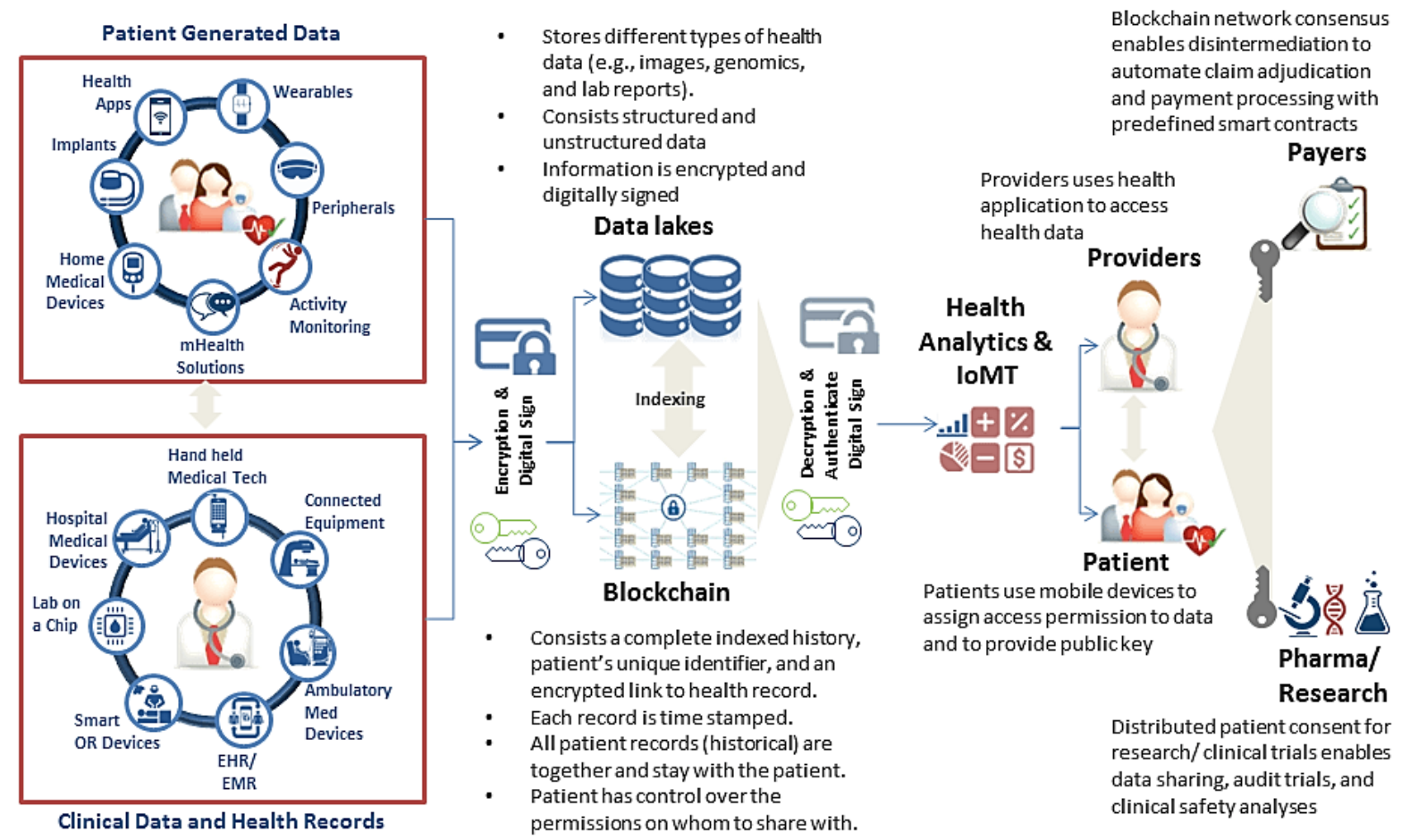

Fig. 3. Blockchain Technology - Promising Use Cases For The Healthcare Industry

(Frost \& Sulivan as cited in [7])

In the end, it is not a matter of how the technology works, but rather a matter of the impact the technology will have. Currently, people are making the same mistake they did with the Internet in the 1990's: they are concerned with the hype aspect of the blockchain and its technological functioning, with the aim of, at a later stage, better understanding potential use cases [7]. Of 3.2 billion web users, how many do not know what TCP/IP, MySQL or Javascript are? Still, they do smoothly browse the Internet and use it for business purposes. The developers are concerned with technological development, while leaders are concerned with its use. As a result, this research shall not focus on how to implement blockchains within industries or organisations, on the legality of the process, or even on its technological aspect. The paper will rather study the general implications for organisations to make use of the blockchain technology, especially in the event of a blockchain-economy.

\section{4. Shortcomings In The Current Economy}

We explained that the blockchain technology is a way to provide underlying trust at every level of the society. In the context of an organisation, it means that it enacts trust among members and also among stakeholders: everyone has confidence each party will act with integrity, thereby trusting the organisation itself. However, because of the reliability of the platform, as well as its decentralised and distributed aspects, the use of the technology will impact firms to a larger extend. The rest of the paper assumes organisations adopted blockchain technology, so that their entire value chain, as well as internal and external transactions occur on a blockchain platform. Table 1. lists the pitfalls that currently affect organisations. At the same time, it depicts how the adoption of a blockchain infrastructure might affect those shortcomings. All are problems that relate to trust, security, privacy, administrative procedures, or power aggregation, which were mentioned in the previous sections. The upcoming section will further detail some of those issues and explain why and in which way adopting a blockchain infrastructure may be a solution. Understanding why the existing system is ineffective is crucial to fully grasp the favourable repercussions of blockchains on organisations and economies. As Eric Cohen, Keyrus CEO stated [35]: "The war of the collaborative platforms has begun. The possibilities opened up by the Blockchain seem limitless. Let us use its architecture to build the foundations of an exponential collaborative economy!" 
Table 1

Shortcomings in the current economy opposed to the benefits brought by a blockchain infrastructure. Own Depiction

\begin{tabular}{|c|c|}
\hline Shortcomings in the Current Economy & Blockchain Economy \\
\hline \multicolumn{2}{|c|}{ Managerial Practices } \\
\hline $\begin{array}{l}\text { Aggregation of power and information by intermediaries; } \\
\text { Centralisation of authority }\end{array}$ & $\begin{array}{l}\text { Decentralisation of information and power; } \\
\text { Distribution of authority }\end{array}$ \\
\hline $\begin{array}{l}\text { Strong hierarchical situations (Top-Down); } \\
\text { Low agility in decision practice }\end{array}$ & $\begin{array}{l}\text { Flattening of organisation; } \\
\text { High agility and adaptability }\end{array}$ \\
\hline Poor collaboration and communication across departments & Collaborative and communicative platforms \\
\hline High transaction costs & Elimination of intermediaries and automation \\
\hline Costly and time-consuming back-office / administrative tasks & Traceable and automated transactions \\
\hline Poor understanding and monitoring of cost structure & Scrupulous costs identification and monitoring \\
\hline Low synergies intra-organisation and across industries & Making use of excess capacity \\
\hline Complex supply-chain management and control & Supply Chain Integrity and Provenance \\
\hline $\begin{array}{l}\text { Low integration of digital economy (loT, Semantic web, chatbots, } \\
\text { big data) }\end{array}$ & Secured ledger enables full digitalisation of data and services \\
\hline Poor or complex contract enforcement & Self-executing transactions \\
\hline Local scope and scale / Poor Inclusion & Universal Global Scope and Scale \\
\hline Complex human resources and procurement & Low Search Costs; automation of administration \\
\hline Complex and costly capital & Low capital raising through smart-contract \\
\hline $\begin{array}{l}\text { Poor security \& privacy; } \\
\text { Low trust across members and organisation }\end{array}$ & $\begin{array}{l}\text { High security \& privacy: control over data; } \\
\text { Members trust each other }\end{array}$ \\
\hline \multicolumn{2}{|c|}{ Leadership Practices } \\
\hline $\begin{array}{l}\text { Poor leadership practices: poor vision \& inspiration; } \\
\text { Focus on managing and efficiency }\end{array}$ & $\begin{array}{l}\text { Focus on leading / coaching } \\
\text { Effectiveness as a goal }\end{array}$ \\
\hline Poor performance tracking and evaluation & Reliable tracking, rating and debriefs \\
\hline Lack of engagement of employees & Active engagement towards achieving the organisation's vision \\
\hline Poor understanding of experts' practices by management & The leader trust and coach employees to perform their job well \\
\hline Focus on structure, stability and linearity of processes & $\begin{array}{l}\text { Focus on ideas and perceptions; dynamic and non } \\
\text { linear orchestration of processes }\end{array}$ \\
\hline $\begin{array}{l}\text { People as object recipients or objects for orchestration of value } \\
\text { creation }\end{array}$ & $\begin{array}{l}\text { People as members, agents and co-authors of value creation } \\
\text { orchestration }\end{array}$ \\
\hline $\begin{array}{l}\text { Information Asymmetries \& Moral Hazard; } \\
\text { Managers as agents of owners }\end{array}$ & $\begin{array}{l}\text { Transparency and accountability of management; } \\
\text { Managers as intermediaries / executors of owners }\end{array}$ \\
\hline Poor exploitation of collective intelligence and creativity & Focus on collective intelligence and enhancement of creativity \\
\hline Absence of bottom-up communication, feedback and debrief & Peer-to-peer interaction; Emphasis on feedback and debrief \\
\hline
\end{tabular}

\section{The Impact Of Blockchain On Organisations}

\section{1. From Concentration To Decentralisation}

\section{1. 1. Distribution of power and authority}

The current functioning of most organisations is simple: a hierarchical structuring of the power makes managers bosses at different levels and experts in each fields are employees. Current organisations aggregate information and power [10]. They also have low levels of automation. Managers currently focus on aggregating data in order to study them and optimise their cost structure: it is exactly what big data inside firms is about. Employees are not networked and are expected to work at the office. Although a shift towards cloud-computing, ICT-use and co-working currently takes place, it remains marginal [36]. There is little possibility for an organisation to be decentralised when it comes to its power, for the main function of the organisation is to precisely centralise power, and aggregate information and activities, which are then to be managed and coordinated. This translates into great transaction costs. The use of a blockchain platform 
by the firm and to a greater extend its inclusion into a blockchain economy, would decentralise power and activities, as previously explained [10]. This should significantly impact transaction and coordination costs.

\section{1. 2. Peer-to-Peer Collaboration}

The introduction of simple smart contracts into and between firms or any other type of organisation will lead to a certain level of automation e. g. automatic payment of supplier at delivery. Furthermore, we previously supposed that companies could likely implement systems of smart complex contracts, which would regulate any transactions inside and outside of firms [10]. This would involve a longer, more complex, negotiation stage where all possibilities of transactions would be provided for. Those system of smart-contracts, upon which the organisation would be based, would serve as the article of association. However, thanks to the use of the blockchain technology, those articles would be automatically implementable, without the need for managerial consent or supervision, as it is what the shareholder meeting agreed upon. As a result, the automation in the enterprise would encompass a wide range of transactions: from payment at delivery, to outsourcing of production power; from ensuring the respect of shareholders decisions, to employee selection. Once again, coordination costs are avoided. Jobs which consisted in verifying tasks are eliminated, because they have been automated. Moreover, the power is decentralised, i. e. direct collaboration and communication are at the core of the organisation. In other words, organisation's members no longer have to go through hierarchical situations to resolve issues with each other. They can collaborate, exchange tasks, vote for initiatives or take time off by creating smart contract between each other. Furthermore, if one assumes that the entire organisation will run through such a blockchain platform, it means that communication is also at the core of the organisation. One could imagine chat softwares with different 'rooms', just like the application Slack. The management body would not play a role regarding those matters anymore. Organisations' members could bypass (time-consuming) hierarchy.

\section{1. 3. The New Work}

\section{A. Performance-based Remuneration}

The adoption of a blockchain structure would impact the way employees are remunerated. It would become the organisation's member own responsibility to complete his own work. His entire pay check or part it, would depend on it, for it is now possible to reliably track his performance [37]. An example would be a programmer being paid for functioning code: an algorithm, included in the terms of the smart-contract regulating this precise job, would verify whether the code functions. Remuneration would exist for each line of code functioning. Terms of the work-based remuneration would be negotiated for each new job undertaken. Obviously, such verification seems harder when the work's quality is not something that is as easily verifiable as code. However, keep in mind that the blockchain economy implies a deep integration of big data and Internet of Things (IoT) [1]. As a result, it could become easier to track someone's performance. Also, employee might be more (or less) willing to endeavour certain risky projects, for a responsabilisation of their work would have occurred. Indeed, our society is witnessing an 'un-responsabilisation' of people towards their actions. People are not encouraged to undertake projects because they are taught to fear failure. This would be the result of a complex bureaucracy and hierarchy, which prevent decision-making in the name of prudence, which attributes failure to external causes [38]. Furthermore, the simple fact that employees know that their contributions are reliably taken into account might simply incentivise them to perform better [12].

\section{B. Collaboration}

A distributed peer-to-peer platform enables direct peer collaboration. As stated before, the direct collaboration regulated through smart-contracts lets members be rewarded for each of their achievement or contribution. It might seem that the negotiation costs for complex smart contract systems would outweigh the benefits they provide. From a small scale perspective, it looks as though one nitpicks over tiny details, which could be resolved afterwards, when the situation occurs. For a small company, processing few tasks, i.e. at a human scale, this is true. However, multiply those 
issues by thousands of customers, all having different understandings of each offer, then add the different views employees have over a task, finally include the fact that every person behaves differently: many issues arise and the 'manager' must resolve them because he concentrates power and responsibility. It is not a matter of skills if at a call centre, the employee must deal with his manager every time one's request falls out of his regular procedure; it is a matter of authority and responsibility. If most issues could be resolved beforehand at the negotiation stage, the gain would likely be enormous [39]. Alex and Don Tapscott raise the point that this would lower other costs beyond simple transaction costs [10]. Among others, costs of (re) establishing trusts among organisation members as well as with other stakeholders; costs of coordination; or research costs [10].

Adopting a blockchain structure means to have a peer-to-peer platform, which enacts direct communication and transactions. Therefore, the organisation easily ends up being a collaborative space where each member decides on what to work on, when and how to contribute best, based on its capabilities and desires (Lubin as cited in [12, 40]. Because blockchain enacts trust among organisation members, nothing prevents collaboration; on the contrary it might incentivise it [19]. Now that workers trust the fact that their added value will be acknowledged and rewarded by the system, they do not fear that their colleague will get the credit for their own contribution. Smart contracts are here to prove ownership of ideas within the organisation. It should let and incentivise any member to 'jump-in' to complete a piece of work that needs to get done, as appropriate for her role. This is what Joseph Lubin refers to as "being agile" regarding "dynamic priorities" and this is how he organised his blockchain organisation ConsenSys (Lubin as cited in [10]).

\section{Agility}

Being agile in our ever-changing society is of primary importance. Priorities are constantly evolving, meaning than tasks must be constantly prioritised accordingly. That is why the adoption of a blockchain platform within an organisation ought to be seen as an opportunity. Agility is enacted, which in turns enables the firm to quickly and properly react to a change of situation. Reaction to change is central to the leadership of an organisation, for it leads to stabilisation. Stabilising is one of the central goals of the management function of an organisation [24]. It is an "active accomplishment" undertaken by leaders in order to provide and develop the conditions for collective capability to work and decide [24]. In other words, with a higher agility in the organisation will lead to better and faster decision-making, with less issues and perturbation originating from change in the environment.

To clarify the benefits of the greater agility provided by a blockchain platform, consider the following example:

$X$ and $Y$ both work in a big computer company like Apple.

Engineer X must design a new phone. He is paid via a performance-based remuneration system, tracking its progress in the development of the design (e. g. collective appreciation of the design on the intranet via blockchain-based voting system).

In the meantime, $\mathrm{Y}$, an engineer in the computer department, has a great idea for a new 'home' button for the phone that $\mathrm{X}$ is designing. $\mathrm{Y}$ designs it and uploads it on the Company's blockchain intranet. He especially sends it to $\mathrm{X}$, as he knows $\mathrm{X}$ is working on the design of the phone (it is publicly accessible to see who is working on what via the blockchain-based intranet). Let's imagine he makes a 3D design using the company's own design software that everyone else uses.

$\mathrm{X}$ loves the idea and uses it by incorporating the uploaded design in his own phone design. This design is traceable because it was uploaded and exchanged on the blockchain and X imported Y's 3D design file in his own design project. As a result, Y would be rewarded for the new home button according to a smart contract both would establish: the home button represents a certain percentage of the whole work, Y is rewarded accordingly. Other members could even submit appreciations towards Y's work or how much credit he deserves.

This example demonstrates that such a blockchain-based enterprise incentives collaboration [20]. Ideas are more easily spread, from peer to peer, and each employee feels more responsible of 
his own work because it is performance-based, i. e. they may take the risk of failing. All in all, it may spur innovation and efficiency, as challenges will be vastly stabilised through collaboration and exchange of ideas.

\section{2. Decrease Of Back Office}

Adopting a blockchain-based platform at the core of an organisation does not mean it shall alter its entire structure -at least not in the short term. It does not mean either that actual firms will disappear, being replaced by DAOs that build collaborative projects with no employees and no bosses. Rather, organisations will have the opportunity to re-architect the way they organise value creation [10]. Again, this is something that shall be incumbent upon leaders: they will have to enact and lead the change.

Beyond decentralisation of power, a blockchain-based organisation will have a great deal of automation. As previously explained, smart-contracts self execute when conditions are fulfilled. This means that many administrative tasks will not be required anymore. Payments, invoicing, double accounting or other types of database management are rendered obsolete by the blockchain [37]. All those transactions will be performed in a fast, secure and reliable manner; with no humans involved. In other words, one should first expect a significant decrease of the process dimension of administrative work [24]. This means that back office workload will also drop. In line with the traceability and the inalienability the blockchain offers, computers will easily perform other jobs involving routinised verification tasks as well. For instance, compliance with environmental standards will be checked by the blockchain along the value chain. A product will only get accepted if all the conditions are met.

To make it clearer, let's work through a few examples of the impact blockchain may have on an organisation's functioning and value-chain:

Automation. Smart-contracts can automate many tasks requiring administrative processing. The most obvious application is with accounting: salaries, invoicing and payments may occur in accordance with terms of smart-contracts [10]. That is, payment at delivery only a blockchain-stamped quality control potentially ensuring the products are correct; or salaries paid after completion of the work, as mentioned earlier. However, it does not stop here. For instance, compliance departments will stop the most time-consuming part of their job. That is, systematically (re)checking standards' compliance of the entire value chain. Indeed, thanks to the blockchain, this task could be performed all along the value chain and be ubiquitously accessed; exactly like Everledger with diamonds [21]. Just in the healthcare industry, up to $10 \%$ of costs are fraudulent and up to $30 \%$ of drugs in developing countries are counterfeits for estimated annual losses of $\$ 200$ billion (Frost \& Sullivan as cited in [7]). A blockchain infrastructure within the industry would relieve the administrative work and the accompanying errors and frauds. Such a department may then focus on developing new ideas to comply with higher standards and work along with other departments in order to conceive and implement those ideas. At the same time, they might have to reflect on what information is to be made available to the public, to the organisation only, or to specific persons, in case the company is using those hybrid type of blockchains we mentioned [12]. A potential consequence would be that it created a greater need for direction and vision, in light of the amount of available information. In other words, importance of leadership may grow.

Tasks Decentralisation. Tasks may easily be outsourced by and to the same firm. Indeed, smart contracts make it very easy to outsource tasks to autonomous agents (whether they are firms or individuals). Similarly, it becomes as easy to rent excess capacity in one's own value chain [37]. Gains in efficiency will likely occur, while coordination does not necessarily increase - it actually decreases with the blockchain in the first place. Moreover, the usual rating system permits faster decision regarding outsourcing: the best performer is chosen. Again, a gain in efficiency occurs, without the usual coordination costs involved. The best current example of such outsourcing of everyday's power is 21.co. This company lets people get paid for answering messages. Lets say one would like to contact a Blockchain specialist, instead of messaging him on LinkedIn where he will not necessarily reply, one can message him for a fee he is paid only if he answers. This means that everything, any lack of power, any excess capacity, any free time can be monetised with the 
blockchain technology [37]. The rating system ensures quality, and the automation of payment and contract terms makes it secure, thus easy to monetise. As a result, organisations will need to better identify potential synergies or outsourcing; that is, a constant reorganisation of value creation. Again, strong increasing leadership will be desired in order to provide direction to an organisation more likely to loose sight in its constantly changing environment. Furthermore, thanks to the reliable rating system, the time spent scrutinising various offers is greatly reduced; be it for searching a better supplier or a better employee). It is nearly instantaneous via a big blockchain directory we described earlier. The person in charge of a specific project can decide in confidence where to buy or who to hire by using the platform's directory, without the help of a dedicated (paid) administrator, which would delay the decision-making process [38].

Costs Monitoring. Using the blockchain technology also offers the possibility to monitor costs and performance in a more reliable manner. For instance, effectiveness of social media advertising (e. g. how many people were reached) shall be more reliably evaluated and forecasted. Still using 21.co as an example, monetising Facebook posts could increase potential reach of information, for it would incentivise people to share the ad. Again, in a digital economy, they would be more willing to take this risk than today, because they control their own data [18]. Finally, social or environmental costs could be monitored through evaluation systems existing along the value chain. People could access those data, forcing transparency from the organisation's side, leading to a rating system for the best-in-class organisations [21]. In a similar way, customers could rate performance for each front desk employee.

The point is that the introduction of a blockchain platform at the core of an organisation and its stakeholders, will automatise most administrative tasks performed inside the organisation or with stakeholders. Be it accounting, recruiting, searching or compliance, the blockchain will provide each of them with reliable information and shall ensure trust between all of them. As a result, many time consuming back office tasks may disappear [12]. A shift towards creativity and strategy will likely occur for those tasks: focus on costs optimisation, focus on compliance with higher standards etc. [12].

\section{3. Elimination Of Transaction Costs}

In his 1937 article "The Nature of the Firm", R. Coase identified three different transaction costs: Search, Bargaining and Enforcement costs. He argued that a firm could expand until the cost of performing a transaction outside the organisation exceeded the cost of performing it inside the organisation [41]. Based on previous sections of this paper Table 1 outlined how costs (including transaction costs) might fall thanks to the blockchain technology. In an 2017 MIT article, Don and Alex Tapscott set forth the effects blockchain will have on those transaction costs, considering the 'agency costs' at the same time. That is, the costs associated with the Jensen and Meckling principal-agency dilemma [42]; i. e. agent does not necessarily act in the owner's interest. Don and Alex Tapscott assert that most, if not all of those costs will be eliminated, allowing organisations employ resources on the inside as smoothly as resources on the outside [12].

The search costs have already been briefly introduced in the previous section, where it was shown that they would considerably drop thanks to a decentralised database, the black box concept and a reliable rating system. Any project manager, recruiter or investor will be able to decide rapidly using a vast range of information known to be correct, for they are uploaded on a highly secure, anonymous and distributed database. This is where the blockchain and Big Data meet: because of security and trust, all information may be digitalised. Any connected devices will provide high amount of reliable information [37]. As a result, people, and especially managers, will have to learn how to query the blockchain directories: answers will be exclusive -in a mathematical way, and limited to yes or no [12].

Trust was introduced as the main feature of blockchains. Accordingly, all transactions costs associated with establishing trust between an organisation and its stakeholders could be eliminated [12]. There is no need to be insured towards transacting with stakeholders (e. g. suppliers, customers, debtors etc.), for the pre-condition of the contract will be fulfilled; e. g. customers will be able to pay for the offer. Furthermore, the cost for organisations to secure data will be inexistent, as 
those data will not be theirs: they will exist anonymously on a blockchain platform and detained by their true owner [1]. However, as pointed out by Tapscott, this will have consequences for managers, for there will be much less serendipity, e. g. target potential customers could involve much more analysis. In other words, the focus will be on targeting stakeholders that do not originally fit the profile agreed upon and figure out how to make them fit this profile; e. g. insurance against default, specific offer, worse quality product etc. Other bargaining costs include legal costs of drawing up contracts. Blockchain and smart contracts will facilitate contracting for all parties. However, because of the self-enforcing feature of the contracts, drawing them up will involve much bargain, for changing the terms at a later stage will be much more challenging than it is currently. As a result, while enforcing costs will be inexistent, bargaining costs will persist [12]. Managers and lawyers will need to learn and ensure the audit of blockchain-based agreements. Instead of focusing on enforcing the terms of the contract, parties will only need to ensure that the terms effectively support their intent [43]. The best example is the DAO hack in June 2016: 150 million dollars were nearly lost because of a loophole in the smart contract. Alex and Don Tapscott support the idea that law firms will specialise in providing audited and secure smart contracts, thus dropping the costs for organisations to draft brand new contracts for each transactions [12]. Note that this could significantly save time to managers, for part of their time is actually dedicated to supervising and ensuring that everything went smoothly as agreed.

An example would be a student that cannot buy a car because of his creditworthiness. Thus he does not fit the profile of a customer and is not targeted by car manufacturer X. At the same time, $\mathrm{X}$ is 'saved' because banks provide credits to customers willing to buy a car (serendipity). However, $\mathrm{X}$ could develop a specific offer destined to students with specific adjustable rates leases or ARM. As a result, market studies of $\mathrm{X}$ would now also encompass students and target them because reliable data would exist, combined to a means to ensure creditworthiness and payment.

Despite having the right people, proper contracts and trust, management remains necessary. As described by Coase, this incurs costs of coordinating people, processes and products, in order to create value [41]. Considering the increasing amount of reliable information, as well as the accruing degree of expertise, it may seem that the need of coordination will greatly increase with the use of blockchain. However, it must be noted that, as previously explained, collaboration will occur peer-topeer; that is without involving a manager. As a result, many transactions occur between two experts directly, with bosses not supervising everything anymore. Whether it is positive or negative is irrelevant: adopting a blockchain platform will most likely decentralise the (hierarchical) organisation of an enterprise [10]. In a similar manner, the agency costs will drop. According to Nobel prize winner J. Stiglitz, the more complex a firm, the higher the agency costs [33]. Blockchains decentralised feature shall drop the firm's complexity. Compiled with unprecedented transparency, every member of the organisation including and especially the owners will be able to see inefficiencies, performance and pay gaps within the firm. In other words, managers, as well as any other member of the organisation, will have no choice but to act in the owner's interest, thereby considerably reducing transaction costs. As a result, managers will have to coordinate fewer tasks because of decentralisation of power and authority. However, they will have to focus more on other tasks resulting from this shift of decentralisation; among other embrace owner's perspectives and stronger leadership.

Coase's theorem introduces externalities as inevitable in real-world transactions, therefore leading to inefficient outcomes and bargains, which prevent further growth [41]. However, if blockchains can plummet the costs of searching, contracting, coordinating, and establishing trust, organisations might, not only open-up on the inside, but also establish trusting relationships with new stakeholders. With blockchain, “acting in one's self-interest serves everybody's interests; cheating the system costs more than using it as designed" [10]. It is this underlying trust that changes everything for organisations.

\section{4. Decentralisation, Autonomy And Engagement}

\section{4. 1. The Problem of Hierarchy}

To come to an end with the impact the blockchain technology may have on organisations, this subsection focuses on the consequences of decentralisation from a managerial perspective, and on employees' engagement. 
In the previous sections, we threw light on decentralisation of decision-making and of hierarchical structure resulting from the use of blockchain. What we fail to explain are the benefits it should engender. Beyond the fact that coordination costs will drop, a significant increase in efficiency should occur. This opposes the general viewpoint of scholars, as expressed by Eliott Jaques in the Harvard Business Review: "35 years of research have convinced me that managerial hierarchy is the most efficient, the hardiest, and in fact the most natural structure ever devised for large organisations. Properly structured, hierarchy can release energy and creativity, rationalise productivity, and actually improve morale". Nowadays, this perspective is still widely shared by managers, albeit its inadequacy towards current dilemmas. Indeed, as explained numerous times, in our expert society managers cannot be expected to know better than other members of the organisation. Everyone is an expert in its field and has different perspectives and practices of doing things [24]. As a result, strong hierarchies where managers constantly control employees' work are ineffective. Regardless of how well they structure unified working systems, they do not make sense. It can only lead to constant clash between executives and employees. In order to depict this issue more clearly, Don Tapscott describes the following cartoon of Fig. 4. featuring the famous Dilbert by Scott Adams [10]. The cartoon illustrates well the problem that managers often rise to a position where they lack the knowledge to decide. With strong hierarchies where communication mostly to top-down, it results in ineffective leadership and unsuitable strategies.

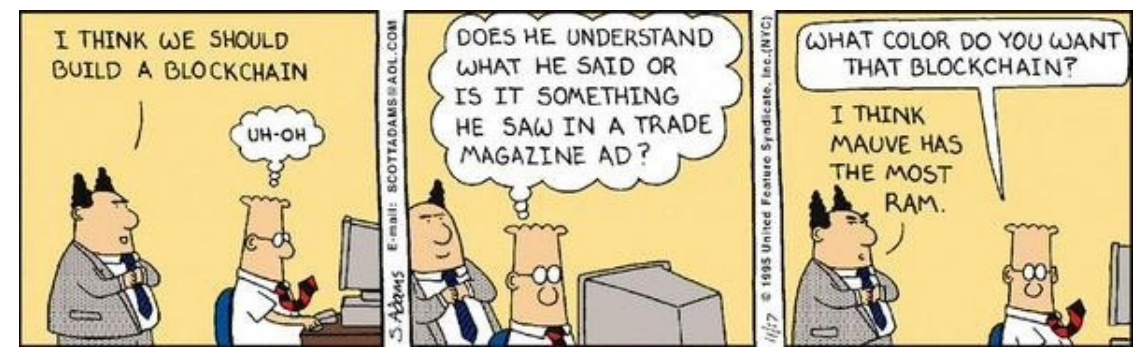

Fig. 4. Dilbert And The Blockchain, in the Dilbert principle originally published in November 1995 to mock the hype development of the databases ("SQL database" was used instead of "Blockchain") and adapted in May 2015 to fit the current blockchain hype cycle (Ken Tindell mashup adaptation from Scott Adams, 1995/2015)

Blockchain gives organisations the opportunity to detach from hierarchies, spur communication and encourage collaboration. It breaks down the top-down barrier because experts can interact directly with each other, without managers intervening. Managers are tasked with empowerment. More and more, companies have tried to distribute power and make hierarchies more flexible. This involves practices such as work at home, co-working, or performance-based compensation. However, the major issue remains trust: how to ensure that employees actually work, or that performance is optimum; how to deal with increasing need of both leadership and tasks' coordination from the manager's perspective? Those are current issues that refrain companies to further implement decentralisation. At the same time, many firms admit that distributing power, responsibility and authority has a positive impact on efficiency and effectiveness [10]. Looking at studies from the working world, it is not comprehensible that authority and responsibilities remain so centralised. Indeed, $75 \%$ of employees are considered to be actively disengaged, meaning that they are "emotionally disconnected from their work" and do not mind enough to go the extra mile [44]. It is of utmost importance to better engage people, in order to increase efficiency and effectiveness in the organisation. Look at Apple that makes engagement fundamental to innovation: it is about changing the world; the Lisa and later the mac team are probably the best example. In the event of decentralisation of authority, the organisation's survival might even depend on engagement. That is why leadership is, more than ever, crucial: it is about empowering people to work actively in, and for the organisation [44]. 


\section{4. 2. Introducing Holacracy}

An increasing amount of data coupled to better forecasts mean more accurate decision basis for strategy. It would potentially increase the need for direction for confused experts. The bottom line of section II.3 is that adopting a blockchain platform and smart contracts will reorganise value creation and transform relationships within the organisation. Decentralisation of power will occur: people will master of their own schedule, own work and will bear most of the responsibilities for both their success and their failures. The role of the technology here is to make all this decentralisation possible. A secure, reliable and trusted platform, which automatically performs transactions, as well as tracks and rewards members for their contributions.

Such an organisation of value creation and hierarchy links us back to an organisational practice named holacracy developed by Brian Robertson in 2001 [45]. Holacracy gives roles to members instead of job descriptions; there is a leader rather than a boss; in other words, people are both a whole and a part [46]. As put by Rud [46], holacracy sends us back to the central notion of agility the blockchain offers: "Holacracy enhances organisational agility by improving the methods used to control organisational activities" [46]. In other words, blockchain implementation enacts holacracy. As explained earlier, the use of the blockchain technology in organisation will contribute to a faster stabilisation of the firm. Or, as Rud states: "it [holacracy] aids rapid and incremental decision-making with maximal information, so the organisation can continue to move forward as new information emerges"; i. e. the organisation stays stable [46].

Nowadays, and this is the issue, organisations still organise value creation as if we were 50 years ago when workers had to perform clear routinised tasks. The world has changed; workers have become experts. Their goal is to create, to mobilise resources and to enhance value production in their own field [24]. Consideration given to scale and complexity, it seems impossible for a manager to overlook each and every task. In addition, it is important to consider that various actors are autonomous and act accordingly: they do not require others to act (Denis \& al, 2001, as cited in [24]). Eventually, it amounts to two opinions fighting over a matter, resulting from different perspectives ("worlds") [47]. Nevertheless, the traditional source of legitimacy often remains hierarchy, when the actual role of the manager should be to trust his employee to do the job well. Even for a similar result, the 'boss' often tries to force his perspective and refuses to acknowledge 'different practices of doing things' [24]. This old conception of structuring work hinders efficiency and effectiveness within the organisation. This is exactly what is implied by the Dilbert cartoon of Fig. 4: because organisations members lack engagement and managers lack expertise, good ideas are often never implemented.

\section{5. Summarising The Transition To A Blockchain Economy}

The thesis is simple. Through the adoption of the blockchain technology, companies will see a decrease in their back-office tasks, and therefore a decrease of their managing tasks as a result of automation and self-executing smart contracts. Many of those changes are listed in Table 1. On that account, managers will have to face new challenges, for their job will be durably impacted. Most likely, they will need to focus more on leading and strategising. At the same time, the research pointed out that decentralisation, power distribution and agility provided by blockchain, combined with the shift towards expert society, will increase the need for direction and therefore leadership in organisations. Executives and other managers might therefore see their roles shift in scope with the emergence of the blockchain technology and of a blockchain economy. The next section aims at describing the potential implications of blockchains on leadership and its practices. It shall further detail the practice of holacracy.

\section{The Effect Of An Increasing Leadership}

Adopting blockchain infrastructure will increase autonomy within organisations. Less back office task should be performed while there should be more decentralisation to handle. The people being 'left alone' with more authority and decision-power than ever (i. e. every member of the organisation: from employees to owners) will need to be inspired to perform their tasks; they will need someone to strictly speaking 'lead them on' and ignite action. 


\section{1. General Assembly As The Effective Supervision Organ}

The inherent problem to the principal-agency dilemma is the existence of asymmetric information between owners and agents [33]. Its consequences, moral hazard or adverse selection, are leadership issues. The shift towards a blockchain infrastructure will force managers to acknowledge they are intermediaries instead of agents [10]. It means that managers ought to brace themselves for transparency in their tasks and behaviours. Because there will not be any significant information asymmetry, they will primarily execute, instead of deciding. The smart-contracts regulating the organisation will ensure they behave according to the rules, for only the General Assembly will have the power to modify them; e. g. $51 \%$ of the people/nodes agree to revise the foundational smart-contract (in general, use the $51 \%$ attack for consensus). Huge gaps between executives' pay and added value will disappear, as the owners will be susceptible to dismiss bad performers [10]. One could imagine a system where the general assembly gives specific power to executives or to the board and records them on the blockchain; e.g. power to hire or fire specific type of people, power to close specific deals, restriction towards the power of engaging in strategy that would oppose specific goals, etc. Everyone will have no choice but to work in the best interest of the company. Proper leadership would, more than ever, be crucial, in order to provide the owners' with the best vision of the organisation's opportunities. Indeed, it must also be understood that owners' non-involvement can also be in the firm's interest. The fact that owners may now be effectively involved in the firm's development ought to be handled with careful leadership providing vision and clarity.

\section{2. Management In Expert Society}

Managers as understood today should not exist in current expert societies. They act as bosses, not as leaders. Instead of inspiring experts to grow within the organisation, they tell them what to do and how to do it. They refuse to acknowledge the expert society, and what comes with it such as 'the different practices of doing things' [59] or 'the relative autonomy of actors' (Denis \& al, 2001, as cited in [24]. This entire task of providing vision is often left to the CEO or the owners alone. With the use of blockchain, decentralisation will provide full autonomy to each expert; the organisation' structure will flatten. As a result, it can only increase inefficiency if no change in managerial practices occur. For instance, a 2014 CEB study reported that $60 \%$ of the strategy officers polled perceived their company's decision-making as too slow, in part because of an excessive focus on risk prevention (CEB/ Gartner as cited in [38]) Thus, risk must be better integrated to increase decisions' rapidity. Hopefully, a blockchain remedies this problem by providing, among other things, accountability.

In Leadership is a conversation, Groysberg and Slind describe the five long-term business trends, which "force the shift from corporate communication to organisational conversation" [48]. They are: Economic Change (shift towards service industries); Organisational Change (flatter and less hierarchical structure - to become even flatter with the implementation of blockchain); Global Change (higher diversity makes communication harder within the organisation); Generational Change (new generations expect more dynamic and peer-to-peer interactions); Technological Change (instant connectivity has become the norm). The shift of an organisation towards a blockchain structure is in line with those pre-conditions forcing the shift towards conversational leadership. Not that it is impossible to do it without a blockchain structure; it is simply that the distributed ledger system requires such type of leadership. The next move for managers should be to become real leaders. It only makes sense when one considers the above-mentioned consequences of a fully implemented blockchain economy. The existing expert organisations still entail managers as directors, as a result of miscommunication and lack of collaboration between experts (i. e. the organisation's members). However, the blockchain-based organisation can do without them, because it eliminates those inefficiencies and transaction costs. Still, it remains that this new organisation cannot exist without strong and constant leadership. As detailed in the previous sections, decentralisation and extreme autonomy of actors will result in confusion of the organisation's members, which will dramatically increase the need for strong, coherent leadership.

Accepting that the organisation can do without bosses is the first step. It is crucial for managers to understand that their current role and practices are not suitable to expert organisations. The second step is developing their leadership skills towards growing into true leaders. 


\section{3. Leadership-In-Action}

This subsection aims at describing the tasks of our new leader in a blockchain-based organisation. To this effect, the study derives the model of Thomas D. Zweifel, the Global Leader Pyramid [49], depicted in Fig. 5, as a frame of references for the "tasks" of an effective leader. The pyramid is consistent with many other leadership models such as the Pyramid Model of Global Leadership adapted from Bird and Osland [50] or the Leadership Pyramid of Pate [51]. It differs from many models, in that it refers to leadership as a set of conversations; approach considered primordial by many scholars such as Harvard professors Groysberg and Slind. Although it is not the dominant approach in the business world, many newly appointed CEOs share this view and now regard leadership as an attitude rather than as a know-how or a trait. Such a posture is suitable with regard to blockchain consequences because, as previously explained, conversations and decisions-in-action are central to a blockchain-based organisation.

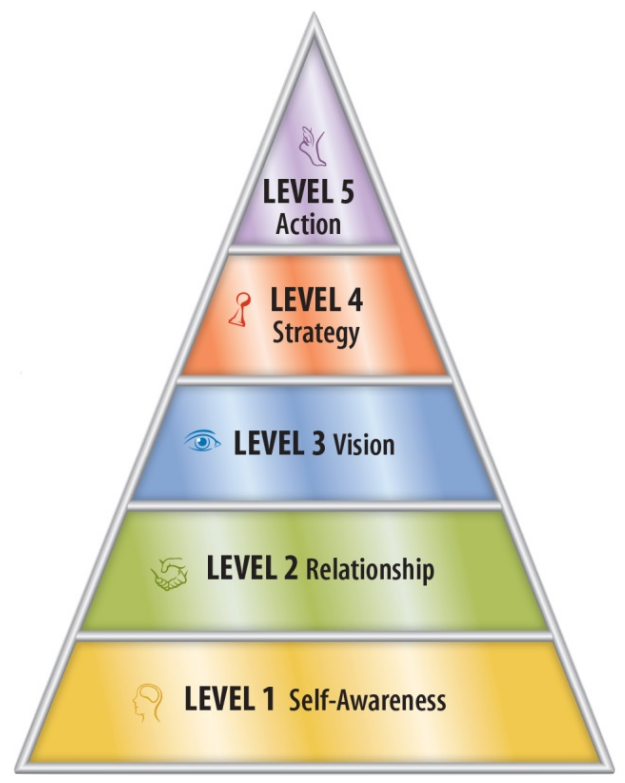

Fig. 5. The Global Leader Pyramid by Thomas Zweifel [49]. It depicts the five levels, from Self-Awareness to Action, leaders should move through to produce meaningful accomplishments

\section{3. 1. Self Awareness}

Self awareness is a personal conversation that unveil one's motives, values and blind-spots, and that gets one centred [49].

It is about self-reflection for both the leader and the members, which affect each other. This includes being aware of its own and others' cultural blind spots or lack of expertise. One of its implication with regard to blockchain technology is the first step mentioned earlier: leaders accepting that the system has changed and reconsidering their role within the organisation. Accepting that the power has shifted from an organisational and hierarchical one to a conversational one. Leaders should be aware of the autonomy of actors, the different practices of doing things, and of their limited span of knowledge. Instead, they should focus on their strength and build their new role within the enterprise accordingly. They should be aware of the coaching each member (i. e. experts) requires due to his high expertise, as well as his cultural mask. Finally, leaders should be aware, but most importantly accept, that conversations may also happen without them.

\section{3. 2. Relationships}

A conversation that builds relationships and deepens trust [49].

It involves strong communication and coordination of ideas, people and projects. Currently managers centralise communication, i. e. information must go through them. This is the wellknown problem of top-down hierarchies where information are barely passed to upper levels, there- 
by leading executives to decide on the basis of a minimum of information [49, 52]. This means that leaders should develop their listening power in order to make informed decisions, as well as engage people so that they report more to them.

In the blockchain organisation, it is a crucial part of the work because the technology provides direct, immediate communication, bypassing managers. It happens peer-to-peer, thereby forcing our leader to listen more to what members report to him. He must also enacts this reporting by fostering communication among members across the organisation. Instead of ensuring that as much information as possible is reported to him, like one should do in a hierarchical situation, our blockchain leader will have to ensure that communication actively occurs between the members of the organisation: everyone should systematically interact and exchange ideas, across departments and offices. For instance, he could moderate numerous Slack discussions to enact collaboration. He should also coach experts and ensure that they actively take part in many projects. The leader will not have to know everything, he will have to ensure that communication is taking place and that people actively engage towards the organisation's purpose.

At the same time, communication implies coordination. In this case, not of work and tasks anymore, but of ideas. Instead of distributing roles and tasks, the leader will need to offer projects to each member, based on of their interests and capabilities. It will be up to them to accept, but it is the role of the leader to convince them that it is the right choice to do so (i. e. to lead them to accept the task). To ensure effectiveness, he will have to target his audience; i. e. listen to the listening [49]. This implies coaching each employee towards managing their tasks and take up new ones for instance. Overall, relationships is one significant aspect of how managers will transform their approach. Even if they remain the bosses from an organisational perspective (e. g. they distribute tasks), they should not impose those tasks anymore. They should communicate and lead employees into accepting them, while fostering collaboration on those tasks.

\section{3. 3. Vision}

A conversation that builds a future for and with people, as well as inspires them [49].

A proper vision drives an organisation. In moments of doubts and confusion, a vision is what people look at to remember what they are trying to achieve. In our blockchain economy, people will likely lose sight of what they are doing. The autonomy of actors, associated with their high expertise makes it difficult to look at the big picture. Added with decentralisation of power, authority and tasks resulting from blockchain technology, confusion will likely arise for every member of the organisation.

The more complex the organisation become, the harder it gets to understand its purpose and values. Currently, a positive side effect of hierarchy and centralised management is that it ensures that people do not lose sight. However, it is not very effective, especially regarding increasing organisational complexity [49]. People's lack of engagement largely arise from a lack of vision, which is the reason why leaders should constantly restore vision [49, 44]. Managers ought to build a vision for our blockchain organisation, but most of all, ensure that it is understood and shared by every member at all time. Establishing and transmitting a vision will not be the job of the top manager/leader anymore, it will also distributed to 'lower level' managers so to speak. Enacting vision should be the job of everyone at every level [44]. Restoring it will be a continuous process, for losing sight is extremely easy with such a high autonomous functioning.

With blockchain implementation, the vision will also be more easily shared. Managers will have to lead everyone into a shared vision, which will be increasingly difficult and time consuming, because they will much more to consider since communication will be much easier. The vision will not stay static and will continuously evolve over time. The job of managers will thus shift from simply building the vision to constantly enacting it and ensuring it is shared; that is understood by every member of the organisation. Otherwise, an underground vision might appear via the peer-topeer communication and collaboration. If the leader does not mind enough about restoring vision, it shall lead to different understandings of the organisation within the same organisation, which would eventually lead to power struggle and collapse. The vision job of our leader will be of utmost 
importance, for without it, the decentralised component of the enterprise makes it so that nothing else maintains the organisation together.

\section{3. 4. Strategy (in-action)}

From a leadership perspective, strategy consists in a conversation that bridges vision and action: it makes the vision do-able and action irresistible [49].

Strategy differentiates into strategy content and strategy process [24]. The former refers to traditional planning of results and goals with a focus on structure, while the latter relates more to the path to achieve the strategy goals with a dynamic focus on ideas and people. Both shape each other, meaning that what affects one dimension, will affect the other. The strategy content and formulation should exhibit less direct impact from blockchain usage. Indeed, conceiving the strategy itself will likely still consists in tools, and identifying basic positioning, as well as strengths and weaknesses. However, more reliable data are available, more ideas are communicated, a better understanding of the organisation as a whole will exist (i. e. strengths, weaknesses or supply chain), allowing for a better decision basis.

Our blockchain implementation should differ in the way strategy is currently orchestrated. The strategy is no more 'for the boss only'. It is explicit-systematic and is the result of managerial work: it becomes "a common achievement of the management" (Nagel \& Wimmer as cited by [24]. Our manager will lead everyone into strategy development, where people act as agents and co-authors of the strategy [53]. It is integrative and comprehensive, as a result of the managers' leadership: micro-politics, employees' coaching, (re)enacting vision, fostering communication and collaboration. This is what Thomas Zweifel and Edward Borey refer to as strategy-in-action [49, 53]. It opposes itself to what is too often the case: 'a strategy plan without a strategy' [54].

The previous sections detailed how adoption of blockchain technology might disrupt the functioning of the organisation. For this reason, the research deducted that strong leadership was crucial to the maintaining of the organisation. However, the different conversations of self-awareness and relationships will also foster even more divergence inside the organisation; i. e. members might be more willing to criticise or to propose new ideas [49]. That is why vision is essential, and so is a clear, consensual and collaborative strategy. Because it is dynamic and systematic, it is considered strategy 'in-action' [53]. The planning and design should be horizontal (instead of topdown) and in continuous evolution; it ties together design and implementation [53]. That is, constantly (re)aligning people and the strategy (goals) together, which will impact the initial strategy formulation [53]. It is the increasing expert collaboration, the peer-to-peer communication, or the distribution of power and authority (i. e. consequences of blockchain adoption), which will force the manager to consult every organisation's member. Everyone will be both agent and co-author of the strategy [53]. Stakeholders need not to agree, they only need to be aligned on the vision deviance actually nurtures creativity $[53,55]$. By connecting perspectives and collecting feedback, our leader/manager will enact and create, collectively, a strategy (process) [53].

A shared understanding of the strategy is the basis. One could imagine that the board of directors, along with the shareholders (thanks to blockchain technology), will remain responsible for creating the basic strategy framework, consisting in the main strategy goals [53]. However, in a firm where the basic plan would be easily shared, managers/leaders will have to lead (i. e. empower) every employee into understanding and accepting this basic strategy formulation [56]. The functioning of a blockchain organisation will make it so that the strategic intent, strategic goals and subgoals, and the indicators of success will be shaped by each member's perspective [53]. Even the attitude of the leader (i. e. its conversations) will be transformed over time through interaction [53]. There will be a continuous evolutionary process for the leader/manager to systematically formulate, enact, reformulate and retransmit the strategy as part of its day to day activities; hence strategy-in-action.

\section{3. 5. Action}

In a leadership context, action is referred as a set of conversation that leads to crucial action and results [49].

Currently, action is mostly referred to as 'acting'; i. e. producing results towards the goals. However, what leadership teaches us is that action relates to the accomplishment of the vision; 
the strategy made real [49]. However, little time is often dedicated to action the way Heidegger would see it: conveying the idea of acting crucially towards the goals of the organisation (Martin Heidegger as cited in [49]. Instead, people seem to focus on doing things for the sake of being kept busy and appearing productive, which is often counterproductive [57]. Those various actions are what one could define as 'unconscious procrastination': small chats, unstructured and unprepared meetings (often here to reinstate vision or countlessly discuss the strategy), daydreaming and hot air, unclear language, or focusing on paper work or email. All of those are undertaken only to gain a mere feeling of achievement, although they contribute in no way to moving the action forward [49].

With blockchains, organisations could gain in clarity. Everyone knows who is doing what, and there is greater awareness of vision and strategy, which prevents their continuous questioning or re-enactment. At the same time collaboration prevents loads of hot air or a switch to unproductive tasks: every idea, every opportunity can be exploited and one can always ask for help or focus on a new task. There is no need to switch to paperwork to feel productive. For a start there might not be much left thanks to smart contracts, and it will be so easy to step-up and collaborate on another, more interesting project. Joseph Lubin explains it is actually quite imaginable that members of blockchain organisations will work on multiple projects at the same time: no time for procrastination [18]. In addition, distribution of authority makes it so easy to reach consensus (without the help of a manager), that decisions will be rapidly taken and implemented. The awareness of members about those decisions will bring further clarity within the organisation. In a similar manner, lack of engagement translates into the same pointless actions and productivity issues [44]. Hopefully, the stronger leadership required in a blockchain organisation should resolve this engagement issue. Finally, performance tracking via the blockchain platform acts as a continuous underlying incentive not to waste energy and time in pointless activities. Even if efficiency in some activities is poorly measurable, the simple fact that everything is made available on the platform fosters employees' engagement. For instance, publicising meeting outcomes on the platform forces members to reflect on what is the purpose of their actions. Moreover, thanks to the rating and communicative system, other members can advertise to the entire organisation including and especially to managers/leaders that those people wasted time and energy.

The point is that, in our blockchain organisation, people will have no choice but to focus on the essence of what the vision and strategy bespeaks to convert it into meaningful action. That is what action is in the sense of leadership [49]. Nevertheless, although it seems that most of the coordination work will occur on its own (through the members' interaction over the blockchain), that is incorrect. The role of our manager/leader remains crucial, for he will conduct the set of conversations, which empowers members to take action. In other words, what he does should lead to action. This includes ensuring things happen as agreed and as formulated. For instance, he will be the one ensuring that people use proper action-directed language [49]. Not only should he ensure that discussions are action-oriented and make sure that each member acts accordingly to the strategy and the vision, he must also serve as a guide in uncertain times. Indeed, breakdowns are inevitable, which destabilises the organisation and make members fear change and disruption. However, breakdowns can be seen as new opportunities to optimise and transform ineffective components within the organisation (Scherr as cited in [49]. Our leader will see and declare the breakdown. Then, he will ask the right questions in order to remedy the breakdowns. Breakdowns will not last long because the leader will actively work towards stabilisation, while, as previously explained in the above sections, the entire decentralised and distributed organisation arrangement will make it so that stabilisation will occur extremely fast. Finally, our blockchain organisation must trust our leader in managing priorities [49].

As a result of decentralisation and automation, priorities will be clearly established and accessible. Members will be able to act towards those priorities. However, the leader will have to be the one that is most aware of them, for he must ensure people act in accordance with those priorities. Managing from priorities start with the formulation, end with the debrief and encompasses many communicative processes in order to lead members into acting from priorities [49]. Something else worth being mentioned regarding action is the importance of debrief; which is, as previously explained, a process our manager/leader will continuously use at every level of the 
Pyramid [49]. Debrief significantly impacts action because it analyses results and helps to derive on what is next and how to do it next time [49]. It is an integral part of the learning process of the know-how of the organisation. While for the previous levels of the Pyramid, debriefs were about collective contribution and alignment fostered by the leader, debriefing action is a process, fostered or undertaken by the leader, which completes a project and directly contributes to the organisation as a whole (rather than to its members) by raising future opportunities [49].

With the adoption of the blockchain technology, managers must respond by increasing their leadership skills. Using the Global Leader Pyramid, we observed that most tasks and roles of managers inside the blockchain organisation imagined in section IV presumably correspond to those of a 'leader'. Moreover, because of decentralisation, automation and distribution of authority, most of the work is to be done 'in-action'. The in-action is central to our new type of leader, for his leadership is not the result of planning. It is a set of conversations that occurs simultaneously, systematically and continuously within the organisation [48, 53]. Citing Clancey in The Being Of Leadership, Wiley Souba sums up this concomitancy: "How one categorises the world arises together with processes that are coordinating physical activity. The actions and interactions of leadership match the being of a leader. Action implies that it is connected to something" [58]. That something is 'being' in the way Heidegger meant it: an active consciousness (Heidegger as cited in [58]). All in all, the work of a manager might eventually switch from a structured work, involving coordination and distribution of tasks, towards a continuous leadership-in-action consisting in igniting action throughout the organisation by behaving as a coach for the members, as described by Thomas Zweifel [49] or Wiley Souba [58, 59].

\section{A Day In A Blockchain Organisation}

\section{1. Harvard Business Review Case Study: Connect}

\section{1. 1. Description of the Case Study}

Section IV and V explained how a blockchain organisation relates to Holacracy; or, at least, enables a similar form of work. ConsenSys CEO, Joseph Lubin, believes holacracy as is should not be implemented because "it feels way too rigid and structured" compared to what a blockchain-based organisation provides [45]. The watchwords of our organisation are "agility, openness and consensus" [10]. That is, spot what must be done, collaboratively decide how to do it, and then distribute the tasks among people willing and eager to perform them, with self-enforcing agreements (i. e. smart-contracts) "that can serve as the glue to hold all of the business aspects of our relationships together" [18]. The job of our manager is now, more than ever, to lead the members of the organisation towards a clear path of accomplishment; to empower them. As put by Lubin, his job is primarily "advisory" [18]: it is about providing a conversational leadership; i. e. enabling awareness, communication, vision, strategy and action [48, 49]. As previously explained, our leader will only enable all the processes composing this leadership-in-action. The aim of this section is to provide a concrete example of how this is done, and why holacracy can be used as a basic framework to detail our blockchain organisation.

The Harvard Business Review case study Is Holacracy For US?, published in March 2017, presents a company discussing a shift towards a holacracy system [38]. The case describes how some executives oppose the shift because they believe autonomy of actors is dangerous. It would lead to a lack of control of the head office on the local strategy implemented by each local manager and local employee, which can significantly hurt the brand in case of pitiful decisions. Indeed, it significantly increases risks, especially in fraud-sensitive regions such as Russia or Africa. The case uses an example, where the company lost money and reputation because of lack of control over its Russian office. At the same time, many board members advocate for an increased autonomy: "No one at an office in Eindhoven can know exactly how complete a job in Turkey" [38]. They believe that the actors most affected by the issues, knowing all the technical features of a project, will be able to make quicker decisions, thus leading the firm to be "much more agile", without being "hindered by needless bureaucracy" [38]. Moreover, the CEO, who leads the shift, views his job not as a coordinator, but rather as a corporate strategist, who should focus on acquisitions and entrepreneurship. 
The point of the case is that the decentralisation the CEO seeks, is similar to the one the blockchain technology enables. It refers to what we previously stated regarding the fact that adopting a blockchain platform and smart-contracts as the basis of an organisation would immediately enact holacracy. Moreover, it would resolve many of the 'control' issues including financial ones in low trust regions especially if an entire blockchain economy exists. However, the reasons advanced by the opponents of the shift such as the CFO remain justified: risk exists with autonomy and decentralisation on the managerial plan. It will not necessarily increase employees' entrepreneurship, engagement or effectiveness; while it could potentially hurt the organisation's reputation or revenues in case of careless or vision- unaligned decisions. It is for this precise reason that leadership-in-action is critical, as highlighted by section $\mathrm{V}$, for it can potentially resolve the issues raised by the present case. The remainder of this subpart will aim at exemplifying how any managers ought to behave in order to resolve those issues.

Rogier, the CEO of Connect, the company at hand is willing to trust his employees and various offices' managers around Europe. He understands that he is no expert in what they are doing and how they are doing it. His primary motivation is obtaining results. Implementing the blockchain in such an organisation would give him the ability to oversee the results and the performance of each office and of each member. Thanks to the blockchain platform, it would be easy to monitor such things as "working capital levels, cash flows, delay reports, claims management, gross margin analysis, cost control, project pipelines", and even to create a people engagement index [38]. As explained before, the technology enables transparent view into and between local units or members, and therefore permits a close monitoring of performance. By using the blockchain, Connect will also emphasises to local leaders and experts that it is in their own interest to share information and discuss problems horizontally [38]: an underlying trust emerges. It proves what was previously stated: implementing a blockchain enacts holacractic practices. However, as explained, although the blockchain is capable of solving transparency issues and tracking performance, it might not necessarily engage members better or prevent corporate risks. This is where conversational leadership (in-action) becomes crucial [48, 49]. To analyse the potential actions of managers and leaders in the blockchain version of Connect, we shall use the leadership framework from Thomas Zweifel that we previously described: the Global Leader Pyramid [49].

\section{1. 2. Applying Results to the Case Study: Blockchain-Connect}

Awareness. The leaders, be it the CEO or a local office manager, will have to make everyone aware of the organisation itself. The complexity of the decentralisation will make it difficult for everyone to understand what they are doing. With more than 30000 projects running in the company at hand, it is crucial that everyone is aware of the greater picture. It will be the role of the local leaders to make the local experts aware of how the entire organisation functions, while it will be the role of the CEO to ensure that all his offices' leaders are credible and trustworthy [38]. The goal is that everyone can answer the question 'why?' [49]. The blockchain platform will make it easy and instantaneous to receive bottom-up feedback. A local expert opinion will be as much taken into account as the one of a corporate leader [1]. With voting systems, self-reflection will be made easier for the organisation: better awareness of the corporate and cultural blind-spots. In the case at hand, it would mean leading the various corporate leaders like the CFO to accept that their role must change because increasing autonomy is necessary. It is also about leading local leaders to take more responsibilities i. e. take the credit and accept the negative consequences. That is, "share information with headquarters, admit when a project isn't going as planned, and recognise how they can improve their business" (Peter Van Mierlo as cited in [38]). Finally, it is about creating a cohesion of perspectives within the organisation: make everyone aware that it is fine to have disagreeing opinions.

Relationships. More emphasis would be put on relationships and communication. Regarding what happened in Russia in the case at hand, a strong communication between the different leaders and experts would have prevented the issue. Here, the autonomy was given without any distribution of responsibility, and no or low communication. The head manager of the office probably was not close to the CEO or any other corporate leader. As a result, trust was extremely low between both 
parties. Rogier should build strong and durable relationships with each local leaders, while every local leaders should do the same with each other and their employees. It is the role of Connect's leaders to foster relationships building. On or off the blockchain intranet, they must all ensure that recurrent communication occurs within the organisation: between the Berlin and Istanbul office, between the CEO Rogier and the Paris manager, among the employees of the Zürich office [60]. All ideas must be exchanged within a context of trust, which is established by the various leaders at the various levels. Needless to say that an underlying trust already exists thanks to the blockchain itself (verified transactions, verified information, tracking of contribution etc.). In the case at hand, the task of the leaders is to enact and explain this culture of trust, synergies and communication.

Vision. In a context of a blockchain organisation, Connect's vision would need to be continuously ensured. Ensuring the vision is crucial in order to prevent the fears of some corporate leaders: lack of engagement from employees, confusion, local missteps etc. The job of all our leaders becomes to ensure the vision is communicated, shared, and adapted to each situation, which can only be the result of the relationships building. It starts with Rogier who should create the company's vision by taking into account the various opinions of local leaders and employees (which is rendered way easier through the blockchain platform). Follows a clear communication to all leaders at both corporate and local levels. All of them are involved in transmitting the vision: they report opinions of members and they inspire them at the same time. The vision might evolve more over time because, for instance, the quickly growing Istanbul office believes that focus ought to be put on the Middle East, as there are substantial growth opportunities in this region. Leaders should therefore ensure to clearly convey perspectives across the organisation, and that everyone understands and shares them because autonomy will reduce the understanding between actors [61]. Each local office and local member should understand what they are part of and be able to see the greater picture: an employee or an office in Bejing should understand how he contributes to the organisation's corporate value, and why he is better-off being part of the organisation. If the vision and the values of the organisation are crystal clear to everyone, while it systematically adapts over the course of time and events, the risk level towards engagement should not increase. On the contrary, because of the underlying trust and communication, there will be a higher commitment from employees to work towards the organisation's vision, leading to what the CFO actually wants: not losing sight of what is going on and containing risks at local levels.

Strategy. We detailed how strategy would occur 'in-action' [53]. That is, after ensuring that there is clarity towards Connect's global strategy, leaders should ensure that the strategy evolves in accordance with perturbations and with the environmental spheres of the organisation. That is, a breakdown or a change of environmental spheres would require a different strategy; i. e. a different path to achieve the vision $[24,53]$. In the case at hand, it would imply that local employees would have the capability to refuse a specific way of doing things because they deem it unfit towards local cultural practices. With such a system, the Russian case would not have happened in the first place, because actions would have been in line with a local Russian strategy, rather than with Connect's 'global strategy'. It is a matter of giving decision-making ability to local leaders and members with on the grounds of familiarity. The office in Istanbul will change its plan if they deem another path is more suitable to achieve the corporate goals. Rogier needs to ensure that this can happen, while the understanding of the main strategy formulation remains the same. At one point, it might be necessary to amend the strategy at the group level if too many offices agree that the conditions have changed and that the original goals can no longer be met. It is also a matter of preserving Connect's reputation. As a result, each 'local strategy' must be coordinated so that they do not extensively differ and hurt the brand value. Again, it is the role of each local and corporate leader to use the underlying trust and communication so that active coordination (i. e. in-action) occurs [53].

Action. In the blockchain version of Connect, acting is up to local offices and local experts. The underlying trust resulting from relationships and the blockchain platform, makes the entire company much more agile. It is no more hindered by "needless bureaucracy" and useless supervision [38]. Indeed timing matters; the absence of local authority often prevents acting at the right time. However, the Istanbul office can now undertake a new project without the approval of the headquarters. Thus, it is up to the leaders to foster action within the organisation. It is up to Rogier 
to ensure that local managers are confident enough so that they take initiatives. It is up to local leaders to ensure that experts take action to complete their projects. This is the result of actively engaging people, setting deadlines, and fostering a collective decision-making. Fostering action in such a way increases entrepreneurship within the organisation, which is exactly what Rogier desires. A culture of debrief should also be implemented so that, for instance, the Nigerian office benefits from the learning of the Congolese or the Russian office. With constant debriefs, the company is also more aware of what is going on in each units, thus improving the accountability.

\section{2. The Conversations Of Leadership-In-Action}

We stated that implementing the blockchain technology within an organisation will render it immediately flatter towards communication, authority, and roles distribution. A trusted system exists, so that parties, which do not necessarily trust each other, can still transact with each other through the platform the blockchain. It thereby provides the foundations to enact holacracy and leadership-in-action: trust; systematic, direct and instantaneous communication; decentralisation of power; (anonymous) feedback; performance tracking; etc.

The previous subsection analysed plausible leaders' behaviours inside the blockchain version of Connect. Different leadership practices came to light. Groysberg and Slind classified those practices of leadership into "elements of conversational organisation": intimacy, interactivity, inclusion, and intentionality [48]. They categorise how leaders engage with employees (i.e. the conversations) in organisations with flat hierarchies like our blockchain organisation. It describes the effective conversations that "add value and empower others to achieve their goals" as part of the leader/manager's leadership-in-action [49]. Therefore, it is only complementary to Zweifel's Global Leader Pyramid model [49].

The case study expounded that leadership (in-action) within our blockchain organisation amounts to empowering people to take action, with the technology laying the foundations of such leadership. It is a matter of how the leaders engage with employees and ignite their potential, i.e. the conversations they have. In Fig. 6, Groysberg and Slind's model presents those behaviours as part of the leadership (in action); i. e. how leaders lead.

For instance, Rogier will emphasise listening through direct feedback on the blockchain platform (intimacy). One could imagine 'listening sessions' under the form of standardised feedback form that could be sent to any member. The form would be anonymous (thanks to the blockchain), while respecting feedback principles so that it effectively contributes to one's performance; e. g. "listening to the listening" [56]. Having directly heard from those affected by the issues, Rogier (or any other leader) could (in-action) set out a strategy and take action to resolve those issues. The action part would involve even more communication. It is a matter of intentionality: "how leaders convey the strategy" [48] and how it is implemented. We explained it would be a continuous and collective process involving those that are the most concerned with the matter. One could imagine that clear the blockchain intranet clearly communicates the goals of the organisation. The leaders' conversations ought to coach people to develop their own strategy to achieve those goals. It all happens at a local level. Leaders should continuously engage with every member of the organisation (experts and other leaders) so that they coach each other towards the best path to achieve the goals; i. e. the strategy. The technology enables communication and leaders must engage conversations.

Our blockchain organisation requires leadership that occurs continuously and in- action. This leadership is characterised by its conversations happening at various levels of leadership (i. e. the various levels of the leadership pyramid). Leadership-in-action starts as an in-ward journey that takes a leader to empower collective action and decision-making the genuine and trustworthy power [59]. In our blockchain organisation members are aware of what they are doing and of why they are doing it. They aim at a vision and are involved in strategy and action, which makes them feel valued. Most of all, this leadership engages every member of the organisation: they decide with care because "the sense of community fuels the human spirit" [58]. In blockchain organisations, leadership will occur in-action because it detaches itself from the managerial way of organising people and tasks. The action is not carefully planned by one 'powerful' man; rather, it comes from every member as the result of continuous conversations led by one or several men (the 
leaders) that ignite action. It seems that, ninety years ago in Sein Und Zeit, the philosopher Martin Heidegger had already grasped the significance of in-action:

The call to being [in action] is precisely something which we ourselves have neither planned nor prepared for nor voluntarily performed, nor have we ever done so. 'It' calls, against our expectations and even against our will. On the other hand, the call undoubtedly does not come from someone else who is with me in the world. The call comes from me and yet from beyond me and over me [57].

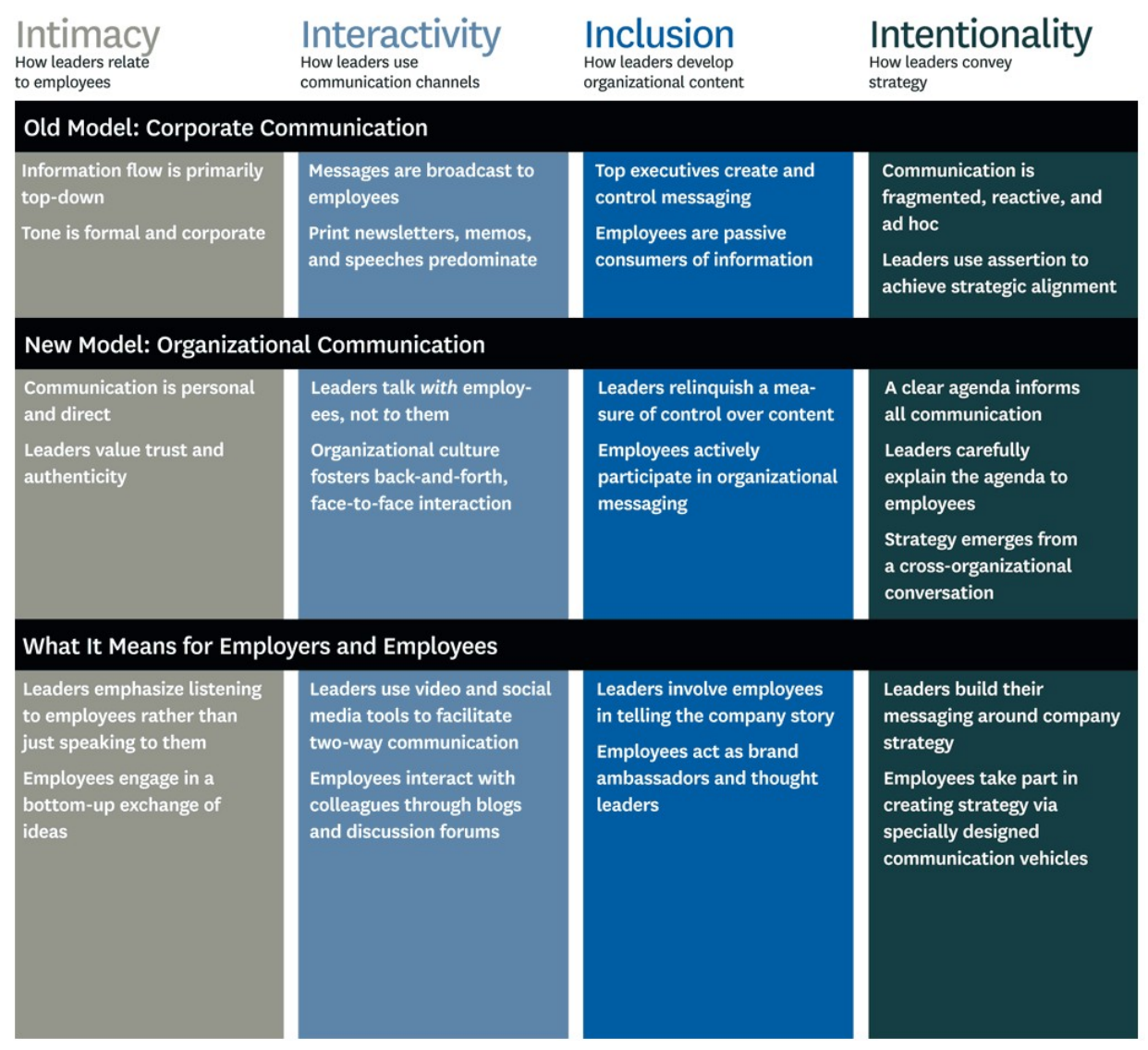

Fig. 6. Elements of Organisational Conversation: how leaders perform their leadership-in-action in our blockchain organisation. Adapted from [48]

\section{Limits}

\section{1. Feasibility}

All things considered, it is only fair to raise the point of the attainability of such organisations: are we going to experience a blockchain economy, and will organisations function is such a decentralised way. The first section of the paper assumed that those would eventually occur. Although this does not question our findings, it might be that the effects are not so widespread.

For a start, the blockchain economy has huge legal implications [43]. Lawmakers need to figure out whether smart-contracts are to be accepted as contracts or as automated performance tools. Figuring-out how to handle the self-enforcing dimension is certainly crucial as arbitration is off the table once terms have started to execute: there is no 'going back' with the blockchain technology. Drafting smart-contracts thus requires the ability to think both like a lawyer and a programmer [43]. In consequence, it will likely take time until the law is able to recognise and arbitrate smart contracts.

The possibility of decentralisation and distribution of authority may also be questioned. Indeed, many experts believe that it is not suited to certain environment because it creates silos, hardly eliminates hierarchy, and is difficult to handle and maintain [38]. Elliott Jaques praised hierarchy because he-rightfully-believed that it is the best system at hand (yet), for it provides ac- 
countability and structure. Nonetheless, it does not mean that the blockchain organisation will not function, because the blockchain organisation as we described it does not oppose Jaques' views on management. Indeed, the scholar explained how managerial hierarchy relates to the complexity of work (i. e. specialisation) and how it can achieve an effective deployment of energy and talent. Namely, he described how hierarchy permitted to meet the four fundamental needs of an organisation: add value throughout the organisation, nail down accountability for each value-adding processes, place people with the demanded competence at the right organisational layer, and build a general consensus and understanding within the organisation to achieve these ends (i. e. enact collective capability to work). Jaques was not wrong to assert that inefficiencies resulted from the poor understanding of how managerial hierarchy structured work with regard to tasks' complexity. He did not oppose the distribution of authority; he opposed the absence of trust, accountability and structure within an organisation. Something that might occur if holacracy was fully implemented as is, without a trusted underlying structuring system (e. g. a blockchain infrastructure). Leadership combined with the underlying trust characterising our ledger fulfils those needs. As a result, although it might be too early to implement such a structure, its viability is established, for it provides the organisation exactly what it entails. As Harvard Professor Yochai Benkler describes it: "it [a blockchain infrastructure] can enable people to function together with the persistence and stability of an organisation, but without the hierarchy" [10]. Of course, there will be detractors, which fight the system and try to deceive it. However, their number will be greatly reduced compared to nowadays, and their interest in cheating the whole system is not necessarily worth it if the rest of their activities depend on its reliability.

The feasibility of blockchain organisations without a blockchain economy is questionable too. Indeed, the functioning of blockchains and smart-contracts might be too disruptive to be adopted as is. When it comes to accounting and payments for instance: the terms of the contracts have to be realisable at any time for it to be validated; meaning that the entire amount should be at disposal when the contract is enforced. The immediateness of payments has further consequences regarding invoices payments: if it occurs through a smart contract with suppliers but not with customers, a problem of cash flow might arise. Indeed, there would be no payables but many receivables. As a result, it is pivotal in such case to have financial services paired with a blockchain based enterprise so that funds are always guaranteed; else it would be impossible to execute a contract, as it would reject any account on credit. It means that the adoption of blockchain systems entails the development of new services not existing in our current models.

Finally, another potential reproach regards the requisite of an integrated blockchain economy. The research took the popularisation of the blockchain technology for granted.

However, there is doubt towards the massive adoption of this technology. It is of general opinion that blockchain technology will indubitably be part of the future [25]. Nevertheless, it might be that it shall only be developed and adopted by institutions, for those same institutions, in the sole interest of security and financial efficiency. The outcomes of the R3 consortium with the private blockchain 'Corda' illustrate that: banks could use it only to eliminate third parties (e. g. clearing houses) and securing transactions between them. This would not affect anyone else but the banks, because the platform is not shared and distributed. Two companies would not be able to transact through a smart-contract over this blockchain to settle their payments, while employees would remain totally unaffected. Such a system does not fit with the principles of efficiency, immutability, security, transparency: that is no blockchain, only a mere encrypted database [16]. In conclusion, the future of blockchain lies in the hand of entrepreneurs, such as ConsenSys CEO Joseph Lubin, willing to transit towards a 'real' blockchain infrastructure at all levels. Once again, it is a matter of leadership: lead the shift towards such a system.

\section{2. The Problem Of Decentralisation}

Blockchain technology is reputed to be inviolable. That is not entirely true. We mentioned how carefully smart-contracts ought to be designed, not to repeat the DAO incident that resulted from a loophole in the founding smart-contract. That could be perceived as a violation of the technology, because it opens the door to potential misuse, where the contract diverges from its 
original intent. Regarding private blockchain, experts often raise the issue that their exclusivity threatens security; e. g. backdoor in the ledger, a network with few nodes attracts hackers to hack the private keys etc. [16]. Moreover, it opens the door to those $51 \%$ attacks: the fewer the number of nodes, the easier it is to modify the entire blockchain. For this reason, solutions involving both a permissioned (private) blockchain and a permissionless (public) blockchain, are perceived as best [62]. It would respect the privacy firms expect, while providing security and transparency to their stakeholders. An example is the already mentioned BTCRelay, which let users transact with BitCoin on Ethereum: a private smart-contract is executed (on Ethereum) but the amount is publicly disclosed (on Bitcoin).

\section{3. The Danger Of A Binary System}

The binary of the system is not a failure or an error. However, it might be a threat to a 'human' world. Indeed, in blockchain economies, people are nodes and not people. Every transactions are based on a trustworthy ledger rather than on emotions, which renders errors prejudicial. Everything will be governed by facts and statistics rather than common sense. Nice bankers or nice bosses would not exist anymore. A loan can only be granted on the basis of one's creditworthiness, which would be calculated based on the available data and statistics. A simple fact or misunderstanding can change everything in a contract and nothing can stop them. No exceptional procedure can be granted if the terms do not encompass the situation. That is why the large scale implementation of the technology can be considered a threat if it is not properly used. This is also another reason for which the public dimension of the technology is essential: it gives the possibility for people to come together and fight if something went wrong. The DAO hard fork showed it in 2016 when the Ethereum blockchain was simultaneously modified by all the nodes to erase the hack of the DAO in which 150 million dollars were stolen.

\section{4. The Strategy Issue}

Although it would be performed in-action for the most part, strategy formulation as a whole raises issues. We defined the strategy in our blockchain organisation as being both clear and precise. At the corporate levels, its content dimension sets corporate goals, while at the local level, it aims at pursuing projects targeting the corporate goals, with the intend of empowering action to realise those goals. The issues arising regard planning and secrecy. The latter concerns the dilemma of providing accountability and full transparency at all price, even when it might be harmful for the company's strategy. The problem does not pose itself for research or secret negotiations as is. Although the platform requires every member to account for its work, anonymity is at its core. The system would validate the occurrence of the tasks without revealing anything else. Moreover, one could think of the possibility to classify projects as secret if it meets certain criteria or if specific persons deem so. Therefore, the dilemma actually concerns the possibility to conciliate the local and the corporate level. It is, without doubt, the role of leaders; however, the required level of awareness and of coordination will be so high, that the practices as we described them might not be sufficient. Secrecy is only one illustration of this issue; coordination of what local leaders gather is another.

Imagine that the sole existence of some projects in R\&D cannot be divulged. The corporate leaders, aware of the product existence, would shape the firm's strategy towards this product. However, the rest of the members (owners, other leaders, employees) would not approve of such a strategy because gaps would prevent a proper understanding. Imagining a wild card for certain points of the strategy would amount to (1) getting back to square-one by giving orders, and (2) asking a very high self-awareness from the members, for they would need to constantly question the plan to get centred i. e. "why?" [49]. There would be a failure for some people to understand the organisation, which would fail the organisation itself. As a result, the idea of a 'two-tier' organisation may emerge, so that all leaders are aware and trusted with the entire strategy, and therefore aware of what may be divulged or not. It would, however, require them to dedicate more to orchestrating the strategy. They could gather often altogether to discuss and plan the strategy so that it can be clearly 
understood regardless of the confidential features; and afterwards communicate and disclose only what was agreed to the rest of the organisation. Such a system could be perceived as the purposeful creation of a new type of information asymmetry. On that account, it might be of interest to further investigate the strategy process and planning in a blockchain organisation, for many problems seem to arise towards coordination and orchestration.

\section{5. Missing From The Research}

One must bear in mind that the complexity of the technology, as well as the overview of the situation performed in the first two sections of the paper prevented the research to go into detail of many implications:

Talent Search. Critical skills could be better and faster identified, which would make it easier to decentralise tasks and distribute authority, because there is confidence in the fact that the system provided the organisation with the rightly skilled person.

Leadership. The paper could have further developed the leadership conversations or how leadership in action occurs. For instance, catalytic actions that could be performed in blockchain organisations (via tracking and collaboration). Other features of leadership enabled by the blockchain were only briefly mentioned, such as the power of people. The different types of leaders were purposefully not explained in details, as it was decided not to research the managerial-side of structural evolution of organisations with blockchains. Furthermore, leadership as described is an attitude and not a knowledge, which makes it difficult to grasp if it is not experienced through catalytic actions-thus preventing a precise and formal description in the context of a blockchain organisation.

Disrupting Feature. Our society and our economy are strongly hierarchical. Therefore, the flattening of interactions would also disrupt economies and societies as a whole. Our society exhibits profit through the exploitation of imperfect information: "Scientia potentia est" [Knowledge itself is power] as F. Bacon said [63]. By including everyone in the economy (low entrance costs) and by drastically reducing information asymmetries, a blockchain economy will disrupt the current power distribution and its abuse: enrichment of some through the exploitation of others.

\section{Conclusions}

Nakamoto's quote asks one to either understand or believe what the blockchain is. It utterly grasped the hype around the blockchain: instead of developing solutions around it, like ConsenSys does, many, like R3, focus on understanding what it is. The rapid emergence of this technology leaves little time for understanding the technological aspect and it is in no way required to identify future prospects.

Blockchains provide efficiency, immutability, security and transparency and it is all that matters. On that account, the repercussions definitely exceed FinTech, on which focus is usually put. In line with the belief that a blockchain revolution will happen and will lead to a blockchain economy, this study researched what those repercussions would be for organisations, in case they would adopt a blockchain infrastructure at their core functioning. For a start, the system solved the problem of underlying trust that is required to transact in any kind, for a 'leap of faith' is currently required to do so, sometimes leading to deceitful behaviours from counter parties. Because it provides security and confidence to everyone, there is no gain in cheating the platform: the common good is promoted by individual interests. Therefore, if the transition to such a system happens, and it certainly will, organisations would be significantly impacted because roles and relationships inside it would be altered: automated administration, direct peer interaction, etc. This will affect the way value creation is orchestrated and maintained inside organisations: inefficiencies and transactions costs will significantly decrease, at the cost of a stronger need for leadership. This distribution of power is actually justified towards our existing expert society: value creation is maintained mostly through strong hierarchical situations that serve more ego than efficiency. In case of a migration towards such a system without effective hierarchy, there is a great risk that an organisation explodes because of a lack of cohesion and understanding arising from the specialisation degree of each member of the organisation. 
Section IV identified strong leadership as a way to maintain such a distributed organisation together. However, it comes from the fact that leadership lacks in our society nowadays. There is no vision for the civilisation, and, accordingly, organisations also lack vision in their management. As a result, managers perform the jobs of leaders without understanding what it entails. Indeed, proper leadership is a "collective activity that happens at every level of organisation" [44], with the aim of "inspiring people to make sense of day to day activities in the wider context of the organisation (and life); it is about (emotionally) linking their contribution to the purpose of the organisation". Because blockchain infrastructure would lack cohesion and common understanding, leadership would be essential. However, the practices should not go against the idea of a blockchain organisation, which emphasised authority distribution, as well as systematic, communicative and continuous collaboration. Studying from the scratch the possible functioning of an organisation based on blockchains led us to realise that the orchestration of work would occur in a manner similar to that of Holacracy, which is a collaborative and conversational orchestration of work. As a result, the Global Leader Pyramid model framed the 'tasks' of a leader inside a 'blockchain organisation'. This model is in line with the belief of CEOs and scholars that leadership should be conversational; an attitude in the moment rather than the transmission of knowledge as a result of careful planning. Such leadership, which occurs continuously and 'in-action', consists in a set of conversation that ignites self-awareness, relationships, vision, and strategy to finally empower action. The analysis of Connect's case study described those conversations and categorised them according to a specific framework.

"Everyone is a self-managed adult" said J. Lubin. This precise idea summarises the arrangement of work described in the paper. It is about providing what fundamentally lacks in typical organising: agility. It is also about trust: be confident that an employee shall perform the task correctly. The numerous imaginable possibilities offered by the blockchain technology makes it hard to clearly picture what it means in the greater context of life. Not considering the technical aspect of the implementation of blockchains within organisations, entitled this research paper to focus on analysing what it would actually mean to have a blockchain structure; what it would entail to have a system that provides trust, distribution of power, collaboration and communication. The results showed that, more than ever, it would call for strong leadership that inspires and empowers people to act and make sense of their contribution in the greater context of life. This leadership must emancipate what a blockchain structure provides: clarity, communication, feedback, collaboration, valorisation etc. There is no need for managers anymore; instead, there must be leaders to coach each member in their actions, to lead them to perform their tasks well, and to provide coherence between them with the aim of stabilising. Leaders and co-leaders ought to be the sparking-plugs of an organisation: they do not run or pilot the organisation; nonetheless, without them sparking the entire context of work, nothing happens and the organisation crashes. The direction should be the result of a collective process, where leaders only convey various opinions. All in all our blockchain organisation could be a perfect synchronisation of collective and collaborative work featuring a collective self-interest. It would be "just like a murmuration of starlings birds" that makes use of collective power; there would be leadership, but there would be no 'one leader' to quote Don Tapscott one last time [10]. Finally, in an era that tends to go extreme, the repercussions of using the technology without proper, empowering, leadership could be perilous. Indeed, power should not be given to the system but to people, for in a world where the collective is preferred over the individual, the system synchronising all individuals would have the power to direct the collective and destroy creativity-the opposite of the blockchain's core idea; or as Asimov put it:

"The lucky few who can be involved in creative work of any sort will be the true elite of mankind, for they alone will do more than simply serve a machine" - Isaac Asimov [64] on the World Fair in 2014.

\section{References}

[1] Google Trends (2017). Interest over time of Blockchain and Bitcoin. Available at: https://trends. google.com/trends/explore?date=all\&q=blockchain,bitcoin

[2] Jaques, E. (1990). In Praise of Hierarchy. Harvard business review, 68 (1), 127-133. 
[3] Coase, R. H. (1937). The Nature of the Firm. Economica, 4 (16), 386-405. doi: 10.2307/2626876

[4] Groysberg, B., Slind, M. (2012). Leadership is a conversation. Harvard business review, 90 (6), 76-84.

[5] Roberts, D. (2016). Meet the most exciting bitcoin company. Yahoo Finance. Available at: https:// finance.yahoo.com/news/why-21-inc-is-the-most-exciting-bitcoin-blockchain-company-balaji-srinivasan-andreessen-horowitz-200250565.html

[6] Zweifel, T. D., Borey, E. J. (2014). Strategy-in-Action: Marrying Planning, People and Performance. New York:: iHorizon.

[7] Tapscott, D., Tapscott, A. (2016). Blockchain Revolution: How the Technology Behind Bitcoin Is Changing Money, Business, and the World. New York: Penguin Random House, 337.

[8] Zweifel, T. D. (2009). Leadership in 100 Days: A Systematic Self-Coaching Workbook. New York: iHorizon, 187.

[9] Cailliau, R. (1995). A Little History of the World Wide Web. Available at: https://www.w3.org/ History.html

[10] Souba, W. W. (2011). The being of leadership. Philosophy, Ethics, and Humanities in Medicine, $6(1), 5$.

[11] Suberg, W. (2017). We Don’t Need Blockchain: R3 Consortium After \$59 Million Research. The Cointelegraph. Available at: https://cointelegraph.com/news/we-dont-need-blockchain-r3-consortiumafter-59-million-research

[12] Buterin, V. (2015). On Public and Private Blockchains. Available at: https://blog.Ethereum. org/2015/08/07/on-public-and-private-blockchains/

[13] De Margerie, C. (2013). Libre Propos de Christophe de Margerie: Les Entretiens de Royaumont. Available at: https://vimeo.com/96894313

[14] Zweifel, T. D. (2003). Communicate or Die: Getting Results Through Speaking and Listening. New York: SelectBooks, 144. doi: 10.1007/978-3-322-82489-9

[15] Brown, R. (2016). Introducing R3 Corda ${ }^{\mathrm{TM}}$ : A Distributed Ledger Designed for Financial Services. Available at: http://www.r3cev.com/blog/2016/4/4/introducing-r3-corda-a-distributed-ledgerdesigned-for-financial-services

[16] Puschmann, T., Alt, R. (2016). Sharing Economy. Business \& Information Systems Engineering, 58 (1), 93-99. doi: 10.1007/s12599-015-0420-2

[17] Lubin, J. (2015). Interview with Joe Lubin/Interviewer: D. Tapscott. in Blockchain revolution by Don and Alex Tapscott.

[18] Tapscott, D. (2016). Blockchain Revolution - From the Internet of information to the Internet of value. Paper presented at the USI, Paris. Available at: https://www.youtube.com/watch?v=Fqr8_iQv8hU

[19] Asimov, I. (2014). Isaac Asimov Asks,“How Do People Get New Ideas?”. Available at: https:// www.technologyreview.com/s/531911/isaac-asimov-asks-how-do-people-get-new-ideas/

[20] Lee, J. (Ed.) (2016). Impact of ICT on Work. Singapore: Springer Singapore, 218. doi: 10.1007/978981-287-612-6

[21] Araoz, M. (2015). Proof of Existence. Available at: https://proofofexistence.com/

[22] Antonopoulos, A. (2017). Blockchain vs. Bullshit - Thoughts on the Future of Money. Paper presented at the Blockchain Africa Conference. Johannesburg. Available at: https://www.youtube.com/ watch? $\mathrm{v}=$ SMEOKDVXIUo

[23] Cohen, E. (2016). The Blockchain, engine of the collaborative economy. Available at: http:// www.keyrus.com/en/post/?post_pk=3591

[24] Bacon, F. (1864). Meditationes Sacrae (1597). The Works of Francis Bacon, 14.

[25] Dennis, R., Owen, G. (2015). Rep on the block: A next generation reputation system based on the blockchain. 2015 10th International Conference for Internet Technology and Secured Transactions (ICITST). doi: 10.1109/icitst.2015.7412073

[26] Schlager, E., Ostrom, E. (1992). Property-Rights Regimes and Natural Resources: A Conceptual Analysis. Land Economics, 68 (3), 249-262. doi: 10.2307/3146375 
[27] Asimov, I. (2014). Visit to the World's Fair of 2014. New York Times. Available at: http://www. nytimes.com/books/97/03/23/lifetimes/asi-v-fair.html

[28] Siegel, D. (2016). Blockchain - Uses, Domains, Challenges, Implications. London Speaker Bureau. Available at: https://www.youtube.com/watch?v=zaYDrkAMD2k

[29] Everledger, Welcome to the digital vault of the future (2017). Available at: www.everledger.io/

[30] Tapscott, D., Ticoll, D. (2003). The naked corporation: How the age of transparency will revolutionize business. New York: Free Press, 348.

[31] Hirt, M., Willmott, P. (2014). Strategic principles for competing in the digital age. McKinsey Quarterly, 2, 93-108.

[32] Roelofsen, E., Yue, T. A. O., Van Mierlo, P., Noteboom, B. E. N. (2017). Case study: is holacracy for us? Harvard business review, 95 (2), 151-155.

[33] Anderson, C., Brown, C. E. (2010). The functions and dysfunctions of hierarchy. Research in Organizational Behavior, 30, 55-89. doi: 10.1016/j.riob.2010.08.002

[34] Raval, S. (2016). Decentralized Applications: Harnessing Bitcoin’s Blockchain Technology. Sebastopol: O'Reilly, 118.

[35] Masse, D., Carbone, V., Acquier, A. (2016). L'economie collaborative: fondements theoriques et agenda de recherche: PICO. Working paper, Paris, 16.

[36] Curtis, R. E., City, E. A. (2009). Strategy in Action: How School Systems Can Support Powerful Learning and Teaching. Cambridge: Harvard Education Press, 240.

[37] Das, R., Behera, K. (2017). Does Blockchain Have A Place In Healthcare? Forbes. Available at: https://www.forbes.com/sites/reenitadas/2017/05/08/does-blockchain-have-a-place-in-healthcare/\#66ed13041c31

[38] Aschari, O. (2014). How to inspire leaders to grow. Zurich: TEDx Available at: https://www. youtube.com/watch? $=$ BHNIZS6-9zE

[39] HolacracyOne. Holacracy. Available at: http://www.holacracy.org/1

[40] Blockchain - A forward step to secure transaction (2016). ifourtechnolab.com. Available at: http://www.ifourtechnolab.com/category/blockchain

[41] Stiglitz, J. E. (1989). Principal and Agent. Allocation, Information and Markets. London: Palgrave Macmillan, 241-253. doi: 10.1007/978-1-349-20215-7_25

[42] Pate, J. C. (2013). The Leadership Pyramid: Today's Effort Determines Tomorrow's Success. Dog Ear Publishing, LLC, 244.

[43] World Bank. (2013). Inclusion matters : the foundation for shared prosperity. Washington: The World Bank, 273.

[44] Reeves, H. (2017). WalderWyss - Blockchain \& Smart Contracts from a lawyer`s perspective. StartX Nexussquared Blockchain Gathering, University Of Zürich.

[45] ENTERPRISE Ethereum ALLIANCE. (2017). Enterprise Ethereum Alliance - VIsion. Available at: https://entethalliance.atlassian.net/wiki/download/attachments/37151/EntEthVision-v3.1-24February2017.pdf?version=1\&modificationDate $=1488946292762$ \& cacheVersion=1\&api=v2

[46] Nakamoto, S. (2010). BitcoinTalk Forums. Available at: https://bitcointalk.org/

[47] Rud, O. P. (2009). Business intelligence success factors: tools for aligning your business in the global economy. Vol. 18. Hoboken: John Wiley \& Sons, 237.

[48] GrowthPraxis (2015). Blockchain Use Cases: Comprehensive Analysis \& Startups Involved. Let's Talk Payments. Available at: https://letstalkpayments.com/blockchain-use-cases-comprehensive-analysis-startups-invoved/

[49] 21.co. (2017). Bitcoin API. Available at: https://21.co/learn/

[50] Tuckermann, H., Rüegg-Stürm, J. (2013). The St. Gallen Management Model. Paper presented at the Lecture 9 - Management Organisation Environment, St. Gallen.

[51] Tuckermann, H., Rüegg-Stürm, J. (2012). Führung im Spital: Weiterentwicklung der eigenen Führungspraxis auf dem Weg in die Zukunft. SRMDM, 2 (12), 45-52. 
[52] Jensen, M. C., Meckling, W. H. (1976). Theory of the firm: Managerial behavior, agency costs and ownership structure. Journal of Financial Economics, 3 (4), 305-360. doi: 10.1016/0304-405x(76)90026-x

[53] Nakamoto, S. (2008). Bitcoin: A peer-to-peer electronic cash system. Available at: https://bitcoin.org/bitcoin.pdf

[54] Whatsapp adds end-to-end encryption (2016). BBC.com. Available at: http://www.bbc.com/ news/technology-35969739

[55] Bird, A., Osland, J.; Lane, H. W., Maznevski, M., Mendenhall, M. E., McNett, J. (Eds.) (2004). Global Competencies: An introduction. The Blackwell handbook of global management: A guide to managing complexity. Hoboken: Wiley-Blackwell, 57-80.

[56] Bush, M. (2015). Trust in Institutions Drops to Level of Great Recession. Available at: http:// www.edelman.com/news/trust-institutions-drops-level-great-recession/

[57] Buterin, V. (2014). A next-generation smart contract and decentralized application platform. White paper. Available at: https://github.com/ethereum/wiki/wiki/White-Paper

[58] Yermack, D. (2017). Corporate Governance and Blockchains. Review of Finance, 21 (1), 7-31. doi: 10.1093/rof/rfw074

[59] Glouberman, S., Mintzberg, H. (2001). Managing the Care of Health and the Cure of Disease-Part I: Differentiation. Health Care Management Review, 26 (1), 56-69. doi: 10.1097/00004010200101000-00006

[60] Heidegger, M. (1967). Being and Time. Oxford: Blackwell, 592.

[61] OECD Digital Economy Outlook 2015. (2015). doi: 10.1787/9789264232440-en

[62] Tapscott, D., Tapscott, A. (2017). How Blockchain Will Change Organizations. MIT Sloan Management Review, 58 (2), 10-13.

[63] Souba, W. W. (2002). Leadership in Action. Journal of Surgical Research, 106 (2), 225-232. doi: $10.1006 /$ jsre.2002.6493

[64] Swan, M. (2015). Blockchain: blueprint for a new economy. Beijing Sebastopol: O'Reilly, 152. 